\title{
Respuesta del derecho penal al multiculturalismo: un acercamiento a los modelos de tratamiento de cultural defences y culturally motivated crimes y sus niveles de coherencia
}

Criminal Law Response to Multiculturalism: An Approach to the Cultural Defense and Culturally Motivated Crime Models and their Coherence Levels

Resposta do direito penal ao multiculturalismo: abordagem dos modelos de tratamento de cultural defences e culturally motivated crimes e seus níveis de coerência

Jairo E. Lucero P.* 


\section{Resumen}

El derecho penal, en su deber de brindar respuestas jurídico-criminales a los conflictos de la conducta humana, se ha enfrentado a nuevos y variados desafíos derivados de los efectos de la globalización económica y la interconectividad global. Ciertamente, factores como la multiculturalidad -reconocida a través de diversos instrumentos internacionales de derechos humanos-han generado desafíos de gran trascendencia en la teoría del delito, particularmente respecto de las diversas respuestas criminológicas forjadas frente a las justificaciones culturales ante hechos típicos. En tal sentido, el presente trabajo, a partir de la dogmática jurídica como método principal, junto con la técnica del análisis documental, se dirige tanto a presentar los modelos de tratamiento de las conductas culturalmente motivadas como a consolidar una propuesta que permita vislumbrar el grado de coherencia que estos modelos pueden tener frente al respeto del marco jurídico internacional de los derechos humanos y la garantía a la libertad de conciencia, ello con el fin de establecer cuál tratamiento en la teoría del delito protege de mejor forma las cosmovisiones minoritarias, a fin de evitar la homogeneización social.

\section{Palabras clave}

Multiculturalismo; cultural defences; culturally motivated crimes; error de prohibición; opción válvula. 


\section{Abstract}

In its duty to provide criminal-legal responses to human conduct conflicts, criminal law has faced new and varied challenges derived from the effects of economic globalization and global interconnectivity. Indeed, factors such as multiculturalism, recognized by various international human rights instruments, have defied the theory of crime, particularly the various criminological responses to cultural justifications for typical events. Based on legal dogmatics as the primary method and the documentary analysis technique, the present paper aims both to present the treatment models for culturally motivated behaviors and to consolidate a proposal for glimpsing the coherence level of these models with the international legal framework of human rights and the guarantee of freedom of conscience. Thus, we will establish which treatment from the theory of crime best protects minority worldviews to prevent social homogenization.

\section{Keywords}

Multiculturalism; cultural defense; culturally motivated crimes; prohibition error; valve option. 


\section{Resumo}

O direito penal, em seu dever de oferecer respostas jurídico-criminais aos conflitos do comportamento humano, vem enfrentando novos e variados desafios derivados dos efeitos da globalização econômica e da interconectividade global. É provável que fatores como a multiculturalidade - reconhecida por meio de diversos instrumentos internacionais de direitos humanos - vêm gerando desafios de grande transcendência na teoria do delito, particularmente a respeito das diversas respostas criminológicas forjadas ante as justificativas culturais diante de atos típicos. Nesse sentido, neste artigo, a partir da dogmática jurídica como método principal, junto com a técnica da análise documental, dirige-se tanto a apresentar os modelos de tratamento das condutas culturalmente motivadas quanto a consolidar uma proposta que permita vislumbrar o grau de coerência que esses modelos podem ter ante o respeito do referencial jurídico internacional dos direitos humanos e da garantia à liberdade de consciência. Isso com o objetivo de estabelecer qual tratamento na teoria do delito protege de melhor forma as cosmovisões minoritárias a fim de evitar a homogeneização social.

\section{Palavras-chave}

Multiculturalismo; cultural defences; culturally motivated crimes; erro de proibição; opção válvula. 
Sumario: Introducción. 1. Breve panorama del surgimiento del "conflicto criminológico" derivado de la multiculturalidad. 2. Tratamiento penal a la multiculturalidad. 2.1. Entre la culpabilidad y la antijuridicidad. 3. Incurriendo en la coherencia. 3.1. Las nuevas perspectivas de comprensión políticocriminal hacia el multiculturalismo. 3.2. Sistema coherente. 3.3. Sistema medianamente coherente. 3.4. Sistema de escasa coherencia. 3.5. Sistema de nula coherencia. 4. Encrucijadas ante nuevos panoramas. 5. Palabras finales ante un mundo multipolar.

\section{Introducción}

El fenómeno político, social y económico enmarcado en la globalización posee en su relevancia un igual sentido de inexactitud, axioma que solo puede reflejar la inmensa complejidad que tiene este proceso que, al ser más concretamente una realidad -difícil de observar en la completa interrelación de sus múltiples aristas-, evidencia los grandes retos que la ciencia penal afronta al ser la frontera límite a la cual se demanda seguridad. ${ }^{1} \mathrm{~A}$ partir de estas exigencias, los miedos eternos a la pluridiversidad de comunidades han sido deconstruidos por algunos nuevos, en su gran mayoría apenas reconocidos, ${ }^{2}$ situando en esta dinámica a la política criminal en su tarea de ofrecer un coherente flujo de suministro de tranquilidad, ${ }^{3}$ muchas veces ineficaz, a una sociedad cimentada en el estudio del riesgo. ${ }^{4}$

En este escenario, una de las mayores fuentes de inseguridad de la sociedad moderna ha venido por cuenta del flujo migratorio ${ }^{5}$ que, al ser producto -principalmente- de las condiciones económicas diametralmente distantes entre países y los conflictos armados suscitados a nivel global, ha producido un choque jamás visto de interrelación de modelos culturales tratando de encasillarse en un mismo sistema político y económico, el cual soporta sus raíces

1 Todo ello reflejo de la misma evolución de las bases jurídicas del derecho, pues, como señala Pier Giuseppe Monateri, “A quest for the multicultural origins of the 'Western Legal Tradition'”, Hastings Law Journal 50 (2003), p. 23, el propio corpus iuris civilis es una "hibridación cultural mediterránea en la que el aporte del pueblo romano rara vez fue el más sofisticado, siendo este un desarrollo conjunto de préstamos de Egipto y del Medio Oriente". Dicho fenómeno, ya en el siglo XIX, J. Gilson, L'etude du droit romain compare aux autres droits de l' antiquite, Francia, De Gruyter, 1899, p. 28, lo llamó el “Uniqueness Model”, esto es, la coexistencia de varios modelos jurídicos en un solo ordenamiento jurídico producto de la interconexión social no limitada a las fronteras geográficas, lo que repercute, desde lo jurídico, en una "valoración de préstamos". En este sentido: Jairo Lucero, “Desobediencia civil cuestión de tradiciones jurídicas o de composiciones y desestructuraciones sociales", CODEX 1-1 (2015), pp. 109-112.

2 Bettina Weiber, "Prevención mediante el derecho penal: ¿es el derecho penal un medio adecuado contra el omnipresente miedo de atentados terroristas?", en Multiculturalismo y derecho penal, Cizur Menor, Thomson Reuters, 2012. p. 181.

3 Bien anuncia Cornelius Prittwitz, "Sociedad del riesgo y derecho penal", en Crítica y justificación del Derecho penal en el cambio de siglo, La Mancha, Universidad de Castilla, 2003, p. 259, que al analizar a Roxin manifiesta que ya en la primera edición de 1992, abordado el tema de la sociedad del riesgo, en la segunda (1994) le dedicó un apartado completo titulado "Derecho Penal de la puesta en peligro, Derecho Penal del riesgo, preservación del futuro: ¿el fin de la protección de bienes jurídicos?", lo cual da cuenta de que no es una preocupación de hoy, sino un proceso contemporáneo de reconocimiento como sociedad multicultural. Véase también Emiliano Borja Jiménez, "Globalización y concepciones del derecho penal”, Revista Estudios Penales y Criminológicos 29 (2009), pp. 179-180.

4 Francisco Vásquez Vásquez, "Impacto de la globalización en el mundo jurídico", Opinión Jurídica 8-15 (2009), p. 20

5 Raúl Carnevali, “El multiculturalismo: un desafío para el Derecho penal moderno", en Política Criminal 2 (3) (2007), p. 3 
en pilares homogeneizantes derivados de la Revolución francesa y proyectados contemporáneamente en los estándares jurídico-fácticos que constituyen el sistema internacional de los derechos humanos.

En tal medida, al generarse hechos constitutivos de sanciones penales en una sociedad determinada, existe cada día una mayor probabilidad de que diversos colectivos culturalmente disidentes de la mayoría confronten un sistema penal basado en la uniformidad (más aún si se considera el derecho penal como una aplicación de normas perfectas), ${ }^{6}$ lo que arroja no solo resultados miopes frente a la justicia que debe deprecar el resultado judicial, sino también perpetúa el desconocimiento y la desaparición de la riqueza cultural existente en la humanidad. Entonces, es necesario preguntarse: ¿cuál es el modelo penal que mejor puede resolver las conductas motivadas culturalmente, esto es, respetando al unísono el marco jurídico internacional?

Para resolver el problema planteado, la metodología empleada es la clásica de las ciencias jurídicas: el método dogmático. ${ }^{7}$ El presente trabajo se ha dividido en cuatro apartados. En el primero, se abordan algunas de las causas y consecuencias generadas a partir de la multiculturalidad. El segundo se destina a detallar los tratamientos jurídico-penales que se han desarrollado a través de las cultural defences en sede de culpabilidad y, más recientemente, de antijuridicidad. En el tercer apartado se consolidará un teorema de coherencia, en el que a través de lo que hemos denominado opción válvula, calificaremos las respuestas de ciertos ordenamientos jurídico-penales latinoamericanos como más coherentes e incoherentes frente a la cultural defences y los estándares de los instrumentos internacionales de derechos humanos. Finalmente, concluiremos este trabajo con algunos cuestionamientos que deben ser resueltos doctrinal, jurisprudencial y normativamente, pues, como es evidente, el presente aporte tiene el propósito de incentivar el desarrollo jurídico-penal a través de la teoría del delito, y por medio de este brindar respuestas más eficaces a la coyuntura globalizante del hoy.

\section{Breve panorama del surgimiento del "conflicto criminológico" derivado de la multiculturalidad}

Es imprescindible considerar el desarrollo tecnológico como el medio a través del cual la humanidad no solo ha logrado concebir un nuevo rumbo, de trasfondo unísono y en momentos homogeneizante, con dirección hacia una comunidad interconectada, sino también, y de forma paradigmática, redescubrir la ausencia de uniformidad que existe en nuestras sociedades y territorios,

6 Pablo Sánchez-Ostiz, "Principios y reglas como base para un modelo argumentativo intercultural de derecho penal", en Multiculturalismo y derecho penal, Cizur Menor, Thomson Reuters, 2012, p. 43.

7 Hernán Corral Talciani, Cómo hacer una tesis en Derecho. Curso de metodología de la investigación jurídica, Santiago, Editorial Jurídica de Chile, 2008, p. 59. 
y siendo fieles a estas, lograr protegerlas como parte de esa autenticidad que tiene la humanidad en su conjunto. ${ }^{8}$ Es en el marco de esta disyuntiva en que la multiculturalidad se transforma al ritmo continuo de la globalización (interdependiente de las relaciones sociales y económicas de cada periodo histórico), ${ }^{9}$ que en la actualidad se extiende un gran debate entre la necesaria e integra protección de las manifestaciones multiculturales, o, por el contrario, el establecimiento de medidas de alineamiento institucional, si bien no desde una corriente homogeneizadora del "occidentalismo", sí en cuanto a la consolidación de unos límites trazados por la humanidad para su pacífica convivencia y respeto de las dignidades, pues, después de todo, la "misión del derecho penal está en asegurar a sus ciudadanos una convivencia libre y pacífica". ${ }^{10}$

Ante este choque eminentemente ideológico frente a la "gestión de la diversidad", ${ }^{11}$ no podemos desconocer que el reconocimiento de la pluralidad cultural de las sociedades ha conducido a la continua evolución de derecho internacional, siendo necesario reconocer la otredad organizativa, y con esta el respeto a sus formas de autodeterminación política, económica y cultural. De este modo los Estados-nación, otrora enemigos del reconocimiento de sociedades "interinas" dentro de sus marcos territoriales, han dado paso a partir de la segunda mitad del siglo XX a que este reconocimiento se consolide como un derecho, soportado, entre otras, en el Pacto Internacional de Derechos Civiles y Políticos (PIDCP) de 1966, ${ }^{12}$ el Convenio 169 de la Organización Internacional del Trabajo (OIT) sobre pueblos indígenas y tribales de $1989^{13}$ y la

8 Michele Carducci, "El multiculturalismo. Entre círculo hegeliano y constitucionalismo de la alteridad", en Multiculturalismo y derecho penal, Cizur Menor, Thomson Reuters, 2012, p. 90, las llama "contradicciones multiculturales", pues en algunos casos actúa en los términos de la "integración", la cual, desde el paradigma de la nacionalidad, se orienta a la homogeneización con base en la tutela e igualdad de los ciudadanos, mientras, contrario sensu, desde el constructo de la "diferencia y alteridad", se desarrolla un "reconocimiento institucional de Ius praxis inter-culturales en todas las sedes de 'constitución material"'.

9 José Hurtado Pozo, “Derecho penal, multiculturalismo y pueblos nativos", Université de Fribourg, 2014, p. 1, en http://perso.unifr.ch/derechopenal/assets/files/articulos/a_20140608_03.pdf, fecha de consulta: 14 de junio de 2021.

10 Claus Roxin, "El concepto de bien jurídico como instrumento de crítica legislativa sometido a examen”, Revista Electrónica de Ciencia Penal y Criminología 15 (2013), p. 1.

11 Fátima Cisneros Ávila, Derecho penal y diversidad cultural: los comportamientos culturalmente motivados, Málaga, Universidad de Málaga, 2017, p. 14, en https://riuma.uma.es/xmlui/handle/10630/14991, fecha de consulta: 01 de julio de 2021. Añade la autora que estos son principalmente guiados por una ideología, o bien liberal (libertad e igualdad de derechos), o bien comunitarista (pp. 150 y ss.). Así, nos encontramos, o con una ideología en la que "cualquier opción de vida será buena siempre y cuando se haya elegido en un entorno institucional que asegure la libertad individual", esto es, en donde el "papel del Estado se limita a garantizar a cada individuo la posibilidad de elegir su plan de vida, sin que pueda intervenir más allá de este contexto formal para configurar las condiciones de justicia desde un punto de vista material" (p. 153), o bien en aquella que encuentra el concepto liberal de ciudadanía "insuficiente para dar respuesta a las necesidades de la sociedad multicultural", pues debe integrar "exigencias de carácter colectivo, en particular, las que tienen que ver con la eliminación de la discriminación de las minorías sometidas a la hegemonía de la mayoría que ordena la vida pública conforme a su propia visión de la vida buena" (p. 159), siendo indispensable la construcción de un "yo social", pues de este depende "en buena medida su identidad y difícilmente puede desligarse de ella" (p. 160).

12 En cuyo artículo 27 se reconoce el derecho de las personas que pertenezcan a minorías étnicas, religiosas o lingüísticas, compartido con los demás miembros del grupo, a tener su propia vida cultural, a profesar y a practicar su propia religión y a emplear su propio idioma.

13 Cabe recordar que el Convenio 169 de la Organización Internacional del Trabajo (OIT) precisa, principalmente en su artículo 2, que: "los Gobiernos deben promover la plena efectividad de los derechos sociales, 
Declaración de las Naciones Unidas sobre los Derechos de los Pueblos Indígenas de 2007, lo cual evidenció tanto el inmensurable olvido en que estaban las comunidades no asociadas a la comunidad en general (reconocidas dentro de los Estados), como la capacidad organizativa que estas lograron dentro de los Estados para que el reconocimiento de la diversidad sea observado como un necesario punto de quiebre en el "proceso civilizatorio". ${ }^{14}$

La consecuencia de este reconocimiento no pudo ser otra que la consagración, algunas veces de carácter específico en sus ordenamientos jurídicos constitucionales,$^{15}$ otras de forma difusa a través de la ratificación de instrumentos internacionales (o del cumplimiento de fallos de tribunales supranacionales) ${ }_{,}^{16}$ de la existencia de Estados pluriétnicos o multiculturales, ${ }^{17}$ los cuales, como consecuencia, deben armonizar la tensión entre la homogeneización y diversificación de las sociedades ${ }^{18} \mathrm{y}$, en tal medida, regular los peligros que traen los procesos identitarios nacionales, verbigracia, con las nuevas realidades migratorias. ${ }^{19}$

económicos y culturales de esos pueblos, respetando su identidad social y cultural, sus costumbres y tradiciones, y sus instituciones", mientras que en su artículo 5 concibe que "al aplicar las disposiciones del convenio deberán reconocerse y protegerse los valores y prácticas sociales, culturales, religiosos y espirituales propios de dichos pueblos y deberá tomarse debidamente en consideración la índole de los problemas que se les plantean tanto colectiva como individualmente".

14 Para el caso latinoamericano no hace falta extender mayores ejemplos que los acontecidos en Argentina entre 1878 y 1885 con la llamada "Conquista del desierto", o en Chile con la "Pacificación de la Araucanía" llevada a cabo entre 1861 y 1883, lo cual es un fiel reflejo de lo señalado en 1552 por Bartolomé de las Casas en su libro Brevísima relación de la destrucción de las Indias, en el que presenta por vez primera una relatoría sobre la violación masiva de -lo que podríamos llamar en la actualidad- los derechos humanos contra las culturas indianas de las Américas (Enrique Pasillas, "Multiculturalismo y derechos fundamentales en el noroeste de México: el caso de la tribu yaqui", Revista Estudios Fronterizos 19 [2018], p. 3).

15 Como lo señalan, verbigracia, la Constitución Política de los Estados Unidos Mexicanos de 2001 en su artículo $2^{\underline{0}}$ ("La Nación tiene una composición pluricultural"), la boliviana de 2009 en su artículo 1 ("se funda en la pluralidad y el pluralismo político, económico, jurídico, cultural y lingüístico, dentro del proceso integrador del país"), la ecuatoriana de 2008 en los artículos 276 y 380 ("promover la diversidad cultural y respetar sus espacios de reproducción e intercambio"; "configuran la identidad plurinacional, pluricultural y multiétnica del Ecuador"), entre otros.

16 A modo de ejemplo, la Constitución chilena de 1980 no hace referencia a la multiculturalidad de su Estado, no obstante poseer un cuerpo normativo fundamental en materia indígena a través de la Ley 19.253 de 1993, y nuevas promulgaciones legislativas devenidas de la evolución y presión del derecho internacional en la materia, tal como la Ley 20.246 de 2008 (espacio costero marítimo de los pueblos originarios), Ley 20.370 de 2009 (Ley General de Educación, cuyo artículo 4to precisa el “deber del Estado promover políticas educacionales que reconozcan y fortalezcan las culturas originarias") y la Ley 24.417 de 2010 (creó la nueva institucionalidad ambiental, precisando que "los órganos del Estado, en el ejercicio de sus competencias ambientales y en la aplicación de los instrumentos de gestión ambiental, deberán propender por la adecuada conservación, desarrollo y fortalecimiento de la identidad, idiomas, instituciones y tradiciones sociales y culturales de los pueblos, comunidades y personas indígenas, de conformidad a lo señalado en la ley y en los convenios internacionales ratificados por Chile y que se encuentren vigentes") (Jaime Gajardo Falcón, "El multiculturalismo, su recepción normativa y perspectivas en Chile y Bolivia, un estudio comparado", Universidad de Chile, 2012, pp. 116-122, en http://repositorio.uchile.cl/handle/2250/112833, fecha de consulta: 15 de junio de 2021). A esto, claro, se debe añadir que 22 países de las Naciones Unidas han firmado el Convenio 169 que les obliga al reconocimiento jurídico y social de las minorías étnicas pertenecientes a sus naciones, en su mayoría pertenecientes al continente americano.

17 Pasillas, "Multiculturalismo y derechos", op. cit., p. 4; Carnevali, “El multiculturalismo", op. cit., pp. 2-3.

18 Isidoro Moreno, "Mundialización, globalización y nacionalismos: la quiebra del modelo de Estado-nación", Cuadernos de Derecho judicial 6 (1998), p. 19.

19 No sin esto decir que el fenómeno migratorio es contemporáneo, sino más bien, la nueva etapa de esta migración es producto del actual modelo social, político, pero, sobre todo, económico, que ha permitido que el flujo o diáspora migratoria sea exponencial y normalizada, a diferencia de otras etapas históricas (Borja, "Globa- 
En este sentido, la problematización que a nivel criminológico requiere la multiculturalidad exige una observación concienzuda que imposibilite rezagos en las garantías jurídico-penales, pero que a su vez no impida el análisis jurídico de las cosmovisiones, tanto en los tipos penales, como en la teoría del delito. Así las cosas, nos enfrentamos a escenarios en los que pretendemos concebir "culturas mayoritarias", ${ }^{20}$ sin cuestionar la extensión de rasgos culturales que debemos apreciar para siquiera afirmar la existencia de una definible mayoría identitaria, lo cual, además, pone en jaque el sostén de la soberanía basado en una única identidad nacional. ${ }^{21}$

Es de tal manera como algunos ordenamientos jurídicos y constructos jurisprudenciales han tomado dos principales perspectivas para enfrentar criminológicamente los argumentos culturales en la teoría del delito. Los primeros, liderados por la tendencia europea, se enfocan en los delitos provocados por razones culturales - culturally motivated crimes - ${ }^{22}$ (ello en sede del error de prohibición), mientras que los segundos, derivados de la corriente norteamericana, se ocupan de encontrar las circunstancias con las cuales se puede justificar un acto típico que se sustenta en motivaciones culturales - cultural defences $-{ }^{23}$ (depende si se considera insanity defense, diminished capacity o mistake of act). ${ }^{24}$ Ambos exigen la concurrencia de ciertos elementos para configurarse, como la pertenencia al colectivo cultural, su asimilación y compenetración a las tradiciones que fueron determinantes para condicionar su conducta, entre otros, aunque no por ello los hace modelos íntegramente indisociables, siempre que el primero recae en el potencial conocimiento y comprensión de los valores vulnerados del ordenamiento jurídico, ${ }^{25}$ mientras en el segundo, dependiendo de la actuación y el contexto, se determina un eximente de responsabilidad,

lización y concepciones", op. cit., p. 193; Defensoría Penal Pública de Chile, Aspectos culturales de la defensa de imputados indígenas, Santiago, Defensoría Nacional de Chile, 2016, pp. 18, 57, 127, 128.

20 Esto debido a lo expuesto por Alessandro Bernardi, “El derecho penal entre la globalización y el multiculturalismo", Revista de Derecho Penal contemporáneo 4 (2003), p. 23, al preciar que "el riesgo al que se ve enfrentada hoy Europa es de transformarse en una especie de torre de Babel por las diferentes formas de vida y costumbres que se aprecian y la existencia de grupos culturales no siempre deseosos de integrarse a la cultura mayoritaria del país de residencia".

21 Por esta razón Carducci, "El Multiculturalismo", op. cit., p. 85, señala que el constitucionalismo "occidental" ha tenido un contenido de "inmunización del multiculturalismo", en el que se elige una opción cultural "única y univoca, de por sí, no pluralizable", o bien "una manifestación de multiculturalismo unilateral".

22 Defensoría Penal Pública de Chile. Aspectos culturales, op. cit., p. 42.

23 Carnevali, "El multiculturalismo", op. cit., p. 16. Aunque el término no surge de la jurisprudencia, sino de la doctrina. Véase Daiana Chiu, "The cultural defense: Beyond exclusion, assimilation and guilty liberalism", California Law Review 82 (4) (1994). En igual forma, se debe tener en cuenta que los delitos en Estados Unidos se definen en tanto el actus reus (acto culpable), como el mens rea (estado mental culpable), encontrándose en este segundo supuesto los cultural defences.

24 Frente a las clases de defenses: Alison Dundes Renteln, "The use and abuse of the cultural defense", en Multicultural Jurisprudence. Comparative perspective on the cultural defense, Oxford, Hart Publishing, 2010, y Jeroen van Broeck, "Cultural defence and culturally motivated crimes (cultural offences)", European Journal of Crime 9-1 (2001), pp. 21 y ss. Para otra clasificación, entre justification y excuses, ver Cristina de Maglie, Los delitos culturalmente motivados. Ideologías y modelos penales, Madrid, Marcial Pons, 2012, p. 110.

Cisneros, Derecho penal, op. cit., p. 331. 
ya sea por un supuesto de declaración de demencia (insanity), ${ }^{26}$ la reacción imprevisiblemente impetuosa propia de la cultura (provocation excuse), ${ }^{27}$ una capacidad disminuida (diminished capacity, aunque este no genera un resultado inimputable, pero sí condenado por un lesser offens) ${ }^{28} \mathrm{y}$, finalmente, la imposibilidad de cumplir el mandato de la norma (lo más cercano a un error de prohibición, mistake of act). ${ }^{29}$

Estas dos orillas jurídicas de solución dan muestra del proyecto teórico que se encuentra en marcha a partir de la discusión cultural en el derecho penal, no obstante ambos compartiendo el mismo esfuerzo de equilibrar una balanza, bien desde una visión garantista, respetando los instrumentos internacionales frente a la integración de las expresiones multiculturales extendidas en la sociedad, o bien desde una proyección sancionadora, que sin distingo aplica la teoría del delito permitiendo juzgar las prácticas culturales. En todo caso, De Maglie lo llama el equilibrio entre el anfitrión (sistema jurisdiccional) y el huésped (imputado por motivaciones culturales). ${ }^{30}$

Precisado lo anterior, las siguientes líneas se dirigirán a apreciar de qué manera la multiculturalidad, como "multiplicador" de la expansión del derecho penal $^{31}$-de la mano de la globalización, como bien lo afirma Silva Sánchez-, ${ }^{32}$ ha exigido nuevos tratamientos jurídico-penales hacia delitos que se enfrenten a patrones argumentativos culturales, esto desde su acogida en las sedes de la teoría del delito.

26 Por ejemplo, en el caso Kimura, una mujer al tratar de practicar suicidio, llevó consigo a sus dos hijos, pues esto es justificado en su cultura (práctica japonesa conocida como oua-ko shinju). Al haber fallecido sus hijos, su responsabilidad por haber cometido parricidio fue atenuada. Véase Óscar Pérez de la Fuente, "Delitos culturalmente motivados. Diversidad cultural, derecho e inmigración", European Journal of Legal Studies 5-1 (2012), p. 82

27 Por ejemplo, en el caso $\mathrm{Lu}$ Chen se estudió un homicidio provocado por el esposo a su pareja derivado de la infidelidad de la última, conducta que motivó un reproche impetuoso sustentado en su constructo cultural, lo que finalmente generó una disminución de su responsabilidad. Véase De Maglie, Los delitos, op. cit., p. 115.

28 Por ejemplo, en el caso White, el exsupervisor de San Francisco asesinó al alcalde y al supervisor de la ciudad; su defensa se basó en el desequilibrio químico del cerebro de White (Twinkie defense) provocado por la dieta de comida chatarra y depresión. Si bien esta defensa se encuentra prohibida en California, las reglas federales de sentencias (United States Sentencing Guidelines, USSG) la permiten, tanto si la conducta no fue violenta (USSG, §5K2.13), o bien si lo fue (USSG, §5K2.0, enmarcada en la llamada "extraordinary mental condition"). Véase Legal Information Institute, Cornell Law School, "Diminished Capacity”, en https://www.law.cornell. edu/wex/diminished_capacity, fecha de consulta: 15 de junio de 2021.

29 Por ejemplo, en el caso Moua se estudia una violación en el marco de un matrimonio, lo cual es permitido culturalmente por ser en esta indiferente la voluntad de la mujer posterior a la ceremonia matrimonial. Véase Cisneros, Derecho penal, op. cit., pp. 278, 280-281.

30 De Maglie, Los delitos, op. cit., p. 108.

31 Joachim Vogel, "Derecho penal y globalización”, Anuario de la Facultad de Derecho de la Universidad Autónoma de Madrid 9 (2005), p. 113.

32 Jesús María Silva Sánchez, La expansión del Derecho Penal. Aspectos de la política criminal en las sociedades posindustriales, 2ª edición, Madrid, Civitas, 2001, pp. 83 y ss. De ahí que lo llame “derecho penal de la globalización”, concibiendo las vías de configuración (pp. 88 y ss.), los principios de política criminal (pp. 99 y ss.), y los lineamentos en el campo procesal (p. 100). 


\section{Tratamiento penal a la multiculturalidad}

\subsection{Entre la culpabilidad y la antijuridicidad}

La aplicabilidad de un juicio penal por motivación cultural requiere la observancia de elementos que necesariamente deben cumplirse para justificar-defences- un juicio atípico al análisis formal y material devenido de las instituciones jurídico-penales clásicas de la teoría el delito. ${ }^{33}$ En esta medida, una vez cumplidos los elementos exigidos por cada ordenamiento para resolver el juicio penal mediante criterios de razonabilidad cultural (lo cual será objeto de análisis en el siguiente acápite), el subsiguiente análisis, ahora en sede de la teoría del delito, surte de dos alternativas para la ubicación de la conducta típica, ya sea en sede de culpabilidad, o más recientemente en la institución de antijuridicidad.

Claro está -y de forma aclarativa-, al ya no ser él o la operadora judicial un eminente bouche de la loi, la aplicación del paradigma criminológico establecido en la norma para los casos de basamento cultural exige, y casi fuerzan al juez a compenetrar en su fuero interno un constructo ideológico y argumentativo que probablemente, o bien no comprende, ${ }^{34} \mathrm{O}$-en el peor de los casos-derechamente reprocha. Ello por tanto dificulta que el proceso pueda atraer en su análisis y acerbo probatorio, no solo el choque de la perspectiva cultural dispar del individuo imputado y la comunidad a la que pertenece versus las reglas (sociales y jurídicas) generalizadas del resto de individuos, sino también la concreción teóricopenal de catalogar un hecho a partir del grado dañoso que este haya generado a la sociedad, y, en tal medida, o considerarlo típico y antijurídico, o solo típico.

Sopesado lo anterior, el tratamiento más generalizado ha sido la consideración típica y antijurídica del hecho imputado por razones culturales ${ }^{35}$-incluso en la cultural defences norteamericana, ${ }^{36}$ - siempre que a través del error de prohibición se excluya o atenúe la culpabilidad argumentada a partir del principio de la prohibición culturalmente condicionada, la cual requiere dos exigencias mínimas: ${ }^{37}$ i) el sujeto desconoce la antijuridicidad del hecho, y ii) dicho desconocimiento es producto de las condiciones diferenciadas culturales propias

33 Carnevali, "El multiculturalismo", op. cit., pp. 24-25.

34 Pero que puede proyectarse hacia una "interpretación progresiva o evolutiva", en la que "los jueces practican no solo conforme a derecho, sino apelando a la justicia y adaptando las normas a la realidad concreta que se va a juzgar" (Pasillas, "Multiculturalismo y derechos", op. cit., p. 13).

35 Borja, "Globalización y concepciones", op. cit., p. 157. En igual sentido Claus Roxin, Strafrecht. Allgemeiner Teil. Band I. Grundlagen. Der Aufbau der Veerbrechenslehre, 4ta edición, Berlín, Verlag C. H. Beck, 2006, p. 131, precisa: "Hay que pensar, además, que las teorías generales del Derecho Penal y los planteamientos políticocriminales que los presiden (como el principio de legalidad, el principio de culpabilidad y el Derecho Penal del hecho) ya son, desde hace mucho tiempo, objeto de intensos esfuerzos científicos desde la perspectiva intercultural y han conducido a un considerable acercamiento de ordenamientos penales en muchas partes del mundo. Hay que contar, por tanto, con ciertos frutos de un Derecho Penal intercultural".

36 Denominada en este sistema las excuses, diferenciadas de las justifications (asimilables en nuestro sistema a las sedes de culpabilidad y antijuridicidad, respectivamente). Véase Carnevali, "El multiculturalismo", op. cit., pp. 25-26., también: De Maglie, Los delitos culturalmente, op. cit., p. 110.

37 Maximiliano Rusconi, "Política criminal y error de prohibición", Revista Guatemalteca de Ciencias Penales 'Justicia Penal y Sociedad' 4-6, 1997, pp. 73, 75, 76. 
de la comunidad a la que pertenece el sujeto, ${ }^{38}$ en la cual no existe el grado de interiorización de la prohibición y la capacidad de daño. ${ }^{39}$

Ahora bien, es necesario considerar que la repercusión de la ejecución de este principio arribado en sede de la culpabilidad no necesariamente implica un explícito reconocimiento por parte de la política criminal a las diversas cosmovisiones existentes en la sociedad que exigen un juicio diferenciado.$^{40}$ Más bien refleja la atenuación o exclusión de ultima ratio a fin de no impulsar una decisión de reproche injustificado frente a la finalidad subjetiva ${ }^{41}$ hallada en el mens rea, siendo por tanto imprescindible-siguiendo las tesis roxinenas-la práctica de un estudio de necesidad preventivo general e individual. ${ }^{42}$ Así pues,

... no se trata de admitir una eximente de la responsabilidad con base en la vulneración de la identidad cultural, sino de considerar la posibilidad de que la pertenencia a una cultura diferente a la mayoritaria condicione de algún modo la responsabilidad penal de quien comente un delito precisamente por atender las costumbres o tradiciones de su entorno cultural. ${ }^{43}$

Paralelamente, en los últimos años se han destacado construcciones jurisprudenciales que han permitido vislumbrar tanto un cambio de enfoque más amplio al pensar cultural diverso que coexiste con el de la "generalidad" (y desde el cual está basado el sistema criminológico), como también una necesidad judicial de avanzar hacia soluciones teóricas que vislumbren una mejor respuesta a los fenómenos culturales, encontrándose aquella no en el error de prohibición (propio del culturally motivated crimes), sino en una sede previa en la teoría del delito, esto es, en la antijuridicidad. En tal medida, se descarta el análisis preventivo, y se centra en la deliberación de la existencia de daño social cuando acciones culturales se encuentran inscritas en la esfera del ejercicio legítimo de un derecho.

38 Frente a esta segunda configuración del error de prohibición, Eugenio Zaffaroni, Derecho Penal. Parte General, Buenos Aires, Ediar, 2002, p. 736, la concibe como necesaria para la "socialización exótica" que debe tener una comunidad con el autor del hecho, cuando este pertenece a una cultura diferente a la mayoritaria, lo cual debe ir acompañado de "unos patrones de valores distintos a los que inspiran el ordenamiento de carácter estatal". Véase Cisneros, Derecho penal, op. cit., p. 283.

39 Siguiendo las tesis de Rusconi, la Cámara Nacional en lo Criminal y Correccional de Argentina, Causa "A.L.L" del 21 de febrero de 2013, Sala I - 81-13, Juzgado de Instrucción 4/113. Magistrados Alfredo Barbarosch, Jorge Luis Rimondi y Luis María Bunge Campos, p. 2, precisó frente al delito de abuso sexual agravado cometido por un extranjero que "no basta con la mera enunciación de que el imputado es extranjero para configurar un error de prohibición culturalmente condicionado; es menester, además, acreditar cuáles son las pautas culturales aceptadas por la tradición a la que pertenece el imputado, que inciden en la comprensión de la antijuridicidad mencionada".

40 Al respecto, bien precisa Zaffaroni, Derecho Penal, Buenos Aires, Ediar, 2000, p. 704, tratándose del error directo de comprensión y la conciencia disidente, que estos se dan en sociedades complejas culturalmente en cuanto a sus formas y modelos de vida. Así podemos decir que el problema no siempre es el sujeto con la norma, sino que ella entra en conflicto cuando es legislada para ser incorporada en un sector contradictorio, y esto se da a raíz del sistema democrático vigente. Véase Carolina Spósito, "Error de prohibición", Universidad de Belgrano, 2003, p. 21, en http://repositorio.ub.edu.ar/bitstream/handle/123456789/173/95_sposito. pdf? sequence=2\&isAllowed=y, fecha de consulta: 27 de junio de 2021 .

41 Hurtado, "Derecho penal, multiculturalismo", p. 11.

42 Borja, "Globalización y concepciones", op. cit., p. 167. En igual sentido, para una perspectiva teórica de la culpabilidad en el mapa de la teoría del delito, véase Jairo Lucero, "La exculpación como criterio punitivo frente a delitos conexos a la rebelión en contextos de conflicto armado interno: una relectura del quehacer del derecho penal en procesos de pacificación", Revista Derecho PUCP 85 (2020), pp. 329-331. 
Si bien las críticas a esta postura no han sido exiguas, es imposible no advertir que el contenido justificante del acto típico bajo estudio cultural viene a marcar un avance en el razonamiento penal de la teoría del delito, en el que proporciona - para dotar de razonabilidad al sistema normativo ${ }^{44}$ - un carácter de legitimidad al acto reprochado, que justifica su ejercicio, y por tanto omite o modula el daño social, pues esta soporta su respuesta en comprender y respetar la multiculturalidad de la que la misma sociedad -como entidad-está compuesta.

Un ejemplo de la aplicación de esta teoría se vislumbró en la sentencia chilena RIT 138-2015 de 12 de agosto proferida por el Tribunal del Juicio Oral de Calama (el cual inauguró este razonamiento judicial en el país austral), el cual da cuenta de la imputación de un comunero perteneciente a la etnia atacameña de la localidad de Socaire (norte de Chile), por el delito de porte ilegal de armas, cuando este mismo ejecutó dicha acción en razón de sus prácticas culturales devenidas de su labor de pastoreo. ${ }^{45}$ Siguiendo los postulados del jurista argentino Eugenio Zaffaroni, se advierte el deber de reconocimiento que deben tener los funcionarios judiciales de aquellas acciones antinormativas que constituyen al tiempo derechos que no pueden ser negados al agente imputado, dado que estos hacen parte de su ejercicio de libertad social (Considerando 11). De tal forma, al presentarse como derecho, con carácter legítimo, concurre una causal de justificación, que a pesar de generarse un desvalor que contradice el ordenamiento jurídico, ${ }^{46}$ no logra completar el elemento antijurídico del injusto. ${ }^{47}$

44 José María Nacarino Lorente, “Obrar en el cumplimiento de un deber por las fuerzas y cuerpos de seguridad (Correcta utilización de la fuerza policial)", Universidad de Valencia, 2015, pp. 33, 94, en https://core.ac.uk/ download/pdf/71052381.pdf, fecha de consulta: 05 de mayo de 2021; Diego-Manuel Luzón Peña, “Alcance y función del Derecho penal", Anuario de Derecho Penal y Ciencias Penales 42-1 (1989), p. 14.

45 Tribunal de Juicio Oral de Calama, Caso Andrés Arsenio Plaza Plaza, RIT: 138-2015, RUC: 1401069965-8, 12 de agosto de 2015, Considerandos 4 y 10.

46 En el mismo sentido se encuentra el caso Ángel Hugo Velázquez Zambrana, RIT: 27-2015, RUC: 1410018700-1, 2 de marzo de 2015, del Tribunal de Juicio Oral en lo penal de Arica (Chile), en el que se imputó de porte ilegal de estupefacientes a un conductor de origen boliviano cuando este ingresaba a Chile con 16 kilos de hojas de coca en su vehículo. En el juicio se da cuenta de la vinculación indígena a la etnia aymara del mencionado conductor, así como el destino de dichas especies vegetales a la realización de prácticas ancestrales en la festividad de San Juan (celebrada en territorio chileno). Si bien posteriormente el Ministerio Público pareciese prescindir de su acusación de porte ilegal de estupefacientes, y apoya con mayor fuerza una tesis frente al delito de contrabando, por no declarar ni cancelar gravámenes aduaneros, el Tribunal afirma, si bien la concurrencia de tipicidad regida por el artículo 3 de la Ley 20.000, no puede afirmarse que existe, tanto de la comprensión del delito (generando un desvalor en su consagración dolosa), como del daño social, puesto que -afirma el Tribunal- "lo gobierna la ignorancia de la antijuridicidad de la norma" (Considerando 16), pues el bien jurídico tutelado "salud pública" no ha sido vulnerado (Considerando 16). Así las cosas, concluye la sentencia precisando dos interesantes análisis: a) refiriéndose a la importancia de la hoja de coca para el pueblo y rituales aymara, "a la luz de lo preceptuado en el Convenio 169 de la OIT [...] la perito con estudios de posgrado en el extranjero [...] realizó el símil de la infaltable presencia de la hoja de coca en las festividades y ceremonias aymara, como cuando no debe faltar el vino y la ostia en una misa católica, así como el himno nacional en el día de la bandera" (Considerando 19); y b) "en efecto, las normas [...] obligan a que el Estado de Chile garantice el respeto a la identidad de los pueblos indígenas, lo que supone que cuando la responsabilidad penal de sus integrantes deba determinarse, sus particularidades sociales y culturales, deben ser objeto de una ponderación concreta, lo que ocurre en el presente caso con el acusado aymara" (Considerando 17). Finalmente, si bien el fallo se sostiene en la falta de conocimiento de antijuridicidad del imputado, no queda puntualmente claro si la absolución se deriva de un ejercicio legítimo de derecho en sede antijurídica (tesis solo invocada por la defensa), o un error de prohibición en sede de culpabilidad (aplicada por el Tribunal en el Considerando 16).

Enrique Cury, Derecho Penal, Parte General, 9 edición, Santiago, Universidad Católica de Chile, 2009, p. 353. 
Ahora bien, uno de los principales tropiezos que ha afrontado esta postura es el grado de lesividad que puede soportar una justificación cultural en sede de antijuridicidad. En tal medida, no será lo mismo la comisión de un asesinato que el porte ilegal de armas, por lo que se ha postulado como complemento a esta postura una suerte de ponderación de intereses devenida de los denominados "delincuentes de conciencia", ${ }^{48}$ en la que se dispone, por un lado, el ejercicio de la libertad de conciencia, y, por otro, el bien jurídico afectado por el comportamiento cultural, no obstante, claro, siendo un cálculo que debe surtirse de forma específica para cada caso. ${ }^{49}$

En las líneas que siguen, se procederá a consolidar una propuesta que permita categorizar y verificar los distintos grados de coherencia que desde las decisiones judiciales se adoptan frente a las conductas típicas amparadas por condiciones culturales.

\section{Incurriendo en la coherencia}

\subsection{Las nuevas perspectivas de comprensión político-criminal hacia el multiculturalismo}

Dentro de las tratativas existentes en el derecho cultural, entendido este como la evolución jurídica destinada a proteger las diferencias culturales existentes en una sociedad, ${ }^{50}$ es menester considerar el enfrentamiento que desde el umbral teórico se ha suscitado a fin de obtener la mejor respuesta para la protección de las divergencias de cultura dentro de un Estado. En efecto, como plantea Carnevali, encontramos que la corriente liberalista concibe suficiente el cumplimiento de los derechos culturales cuando se garantizan eficazmente los derechos civiles y políticos de todos los ciudadanos, esto basado en el extremo respeto de las libertades individuales, en las cuales no puede existir interferencia alguna del Estado, pues cualquier promoción generaría un agravio a los principios de libertad e igualdad social, siendo por tanto necesario un interés autónomo de cada comunidad para la preservación propia de su identidad. Por su parte, el comunitarismo demanda para dicha protección un respeto por las diversidades culturales de manera particularizada, lo que genera derechos

49 Así, perfectamente puede acontecer que una conducta motivada por la conciencia atente contra un bien constitucionalmente protegido, en el que podría no aplicar la justificación cultural. Véase Diego Manuel, Luzón Peña, “Actuación en conciencia y objeción de conciencia como causa de justificación y como causa de exculpación frente a la punición del delincuente por convicción", Indret 1 (2013), p. 7; Antonia Monge Fernández, El extranjero frente al Derecho Penal: el error cultural y su incidencia en la culpabilidad, Barcelona, Bosch Editor, 2008, pp. 51-52.

50 Manuel Moreira, “El concepto de cultura en el derecho", Revista Civitas 8-3 (2008), p. 467; Daniel Bonilla Maldonado, "Indígenas urbanos y derechos culturales: los límites del multiculturalismo liberal", Revista Direito GV 7-2 (2011), p. 578. 
culturales colectivos hacia ciertas expresiones culturales e implica la consolidación de discriminaciones sobre la base de la pertenencia a un grupo cultural. ${ }^{51}$

En consecuencia, el denominado "contexto social" se posiciona como el centro de la discusión, por cuanto representa el supuesto fáctico-político que se exige al Estado para promocionar la protección de determinadas identidades culturales (tesis comunitarista), o, por el contrario, de omitirlas y garantizar equitativamente todas las garantías jurídicas a todos los ciudadanos (tesis liberalista). ${ }^{52}$

La problemática insertada en esta discusión reside en reducir las dificultades que cada una de estas posiciones circunscribe en sus planteamientos, pues la tesis liberalista omite gravosamente la evidente desigualdad de condiciones políticas y económicas que las minorías étnicas poseen en la gran mayoría de los Estados, siendo un limitante social de tal magnitud que socavar la solución en términos de libertad extrema engendra en su propia tesis los predicamentos de la injusticia; por su parte, la posición comunitarista no logra definir -ni podría hacerlo- las consecuencias que para la diversidad cultural genera el otorgarles a los Estados la facultad de escoger qué manifestaciones etnográficas se deben proteger, lo que posibilita, o bien el nacimiento del germen racista de una nación, cercano a la homogeneización escalonada tras las sombras del garantismo cultural, o un multiculturalismo extremo, llamado también background cultural, que permitiría el uso de la cultural defense en todo tipo de delitos. ${ }^{53}$

Las posiciones teóricas descritas previamente nos arrojan a una disyuntiva entre el respeto de las expresiones culturales, el grado armónico en su promoción (sin transgredir los derechos del resto de colectividades culturales y también sin deformar la cosmovisión misma de la colectividad promovida), y la protección razonable de la identidad nacional (ello si es necesario en términos de integridad cultural) ${ }^{54}$ respuesta que no debe observarse en un simple

$51 \quad$ Carnevali, “El multiculturalismo", op. cit., pp. 10-13.

52 Charles Taylor, El multiculturalismo y la "política del reconocimiento", México D.F., Fondo de Cultura Económica, 1993, p. 52-53; Carnevali, “El multiculturalismo", op. cit., pp. 13.

53 Mario Ferreira Monte, "Multiculturalismo y derecho penal en el espacio lusófono. Prueba de una solución de restauración para el problema de los delitos motivados culturales", en Multiculturalismo y derecho penal, Cizur Menor, Thomson Reuters, 2012, p. 121.

54 Hago referencia a este punto, y sin ahondar en dicho cuestionamiento no siendo objeto principal de este estudio dado que, a diferencia de la creencia general, las características culturales no hacen parte indispensable de la consolidación de un Estado-nación, pues si ello fuese cierto deberíamos reconocer la existencia de 194 culturas con características particularizadas en el mundo, circunscrita cada una en cada Estado. Por su parte, es necesario destacar que la división territorial de cada país debe su procedencia a motivaciones mayoritariamente políticas y económicas, a lo cual, si añadimos el flujo migratorio -y con este, cultural- de grandes dimensiones que presencia la humanidad, no podemos desentrañar una respuesta diferente a que, actualmente, el sostenimiento de los Estados es provocado esencialmente por razones exógenas a las culturales. Ahora bien, esto no quiere decir que la cultura no posee relevancia sino, por el contrario, contiene en su esencia la característica misma de la singularidad del ser humano y su forma de autodistinguirse, siendo de tan inigualable trascendencia que traspasa las reglas herméticas político-económicas soportadas en las fronteras nacionales. Es en tal sentido, como lo afirma Alejandro Jodorowsky, "cuando los países se desmoronan y se caen, lo único que queda de ellos es la cultura, por eso es tan importante", por lo que remataría André Malraux que "la cultura es lo que, en la muerte, continúa siendo la vida" (Emilio Javier Verón Bustillo. La protección del patrimonio cultural contra el tráfico ilícito de bienes culturales, Bogotá, Dykinson, 2017, p. 13). 
posicionamiento en la teoría del delito, pues pasa también por la consolidación de una jurisdicción especial, ${ }^{55}$ equipos interdisciplinarios ${ }^{56} \mathrm{e}$ incluso -a pesar de lo obvio- una línea normativa y jurisprudencial clara para atender los ilícitos cuya motivación proviene de la cultura ${ }^{57}$. Es en tal medida que, en cambio de observar tendencias criminológicas frente al tratamiento de las conductas basadas en la cultura, consideramos más oportuno establecer una categorización que vislumbre el grado de coherencia que el derecho penal, como estructura sostenida en la teoría del delito, tiene frente al derecho cultural como construcción garantística no solo normativa, sino institucional.

Así las cosas, basaremos nuestra tesis en cuatro modelos, a saber: coherente, mediana coherencia, escasa coherencia y nula coherencia.

\subsection{Sistema coherente}

La primera categoría hace referencia a un modelo sociopolítico que integra armónicamente los estándares internacionales de respeto a la autodeterminación de los pueblos, sin ser óbice de ello el apoyo político y financiero de un Estado para que las minorías culturales logren dicho fin, por lo que la implementación de jurisdicciones especiales frente a minorías étnicas permite un real respeto a dichas garantías colectivas y su particular visión del mundo. ${ }^{58}$

Ahora bien, esto no puede tomarse de forma ligera, pues posiciona diversas problemáticas que es necesario cubrir. Las principales se centran tanto en el mal uso de las jurisdicciones o el entendimiento de las instituciones jurídicocriminales para encubrir actos y motivaciones que sean antijurídicas y culpables (tanto en el ordenamiento penal general como en el concebido culturalmente), como también en el difícil ejercicio de establecimiento de límites que permitan la protección de las garantías penales mínimas armonizables con el respeto de los derechos humanos. ${ }^{59}$

55 Véase Manuela Royo, "Derecho Penal e interculturalidad como manifestación del principio de igualdad", Política criminal 10-19 (2015), pp. 370 y ss.; Raquel Yringoren Fajardo, "Pluralismo jurídico, derecho indígena y jurisdicción especial en los países andinos", El otro derecho 30 (2004), pp. 171-195; Will Kymlicka, "Federalismo, nacionalismo y multiculturalismo", Revista Internacional de Filosofía Política 7 (1996), p. 29.

56 Cisneros, Derecho penal, op. cit., pp. 63-64, 186; Juan Jorge Faundes, "Derecho fundamental a la identidad cultural de los pueblos indígenas: un nuevo paradigma en la defensa penal indígena en Chile frente al Estado de Derecho hegemónico", Izquierdas 45 (2019), pp. 63, 68. Una interesante propuesta la trae Beatriz Kalinsky, Justicia, cultura y derecho penal, Buenos Aires, Ad-Hoc, 2000, 156-161, quien señala la necesidad de una prueba antropológica que permita a la jurisdicción arribar a un estudio epistemológico de la cosmovisión de la comunidad indígena.

57 Contrario sensu, la contradicción entre el Tribunal Constitucional español que consideró no antijurídico el actuar de los padres que por convicciones religiosas no convencieron ni otorgaron permiso para que su hijo tuviese una transfusión de sangre, por cuanto admitir sus actos como antijurídicos vulneraría el núcleo de su derecho fundamental a la libertad religiosa (Sentencia 154/2002, del 18 de julio de 2002), mientras el Tribunal Supremo consideró antijurídico y culpable (esto es, tampoco precisó la exculpación) el incumplimiento del deber electoral de ser veedor de una mesa electoral de una persona perteneciente a los Testigos de Jehová (Sentencia 8697/2007).

58 Carducci, "El multiculturalismo", op. cit., p. 90, llega a considerar que este es el mecanismo para llevar a la praxis una "constitución material" desde la "diferencia" y la "alteridad".

59 No podemos obviar que esta posición encuentra sustento jurídico internacional en el mismo Convenio 169 de la OIT, pues en su artículo 8 se precisa que "al aplicar la legislación nacional a los pueblos interesados 
Por ello es indispensable para este primer modelo la existencia de reglas claras que permitan coincidir en un verdadero y legítimo ejercicio de una jurisdicción especial, entre las cuales podemos considerar las propuestas esgrimidas por la Corte Constitucional colombiana frente a los límites que impone a la autonomía de las jurisdicciones indígenas, lo que, aunado al respeto de la Constitución y la ley (consagrado en el art. 246 Constitucional), ${ }^{60}$ entendidas "en primer lugar, por el núcleo duro de derechos humanos, junto con el principio de legalidad como garantía del debido proceso y, en segundo lugar, por los derechos fundamentales, mínimos de convivencia cuyo núcleo esencial debe mantenerse a salvo de actuaciones arbitrarias", ${ }^{61}$ también exige la coexistencia de cuatro factores: i) personal, ii) territorial, iii) institucional u orgánico y iv) objetivo. ${ }^{62}$

En esta medida, el factor personal hace mención a que el acusado de un hecho punible o socialmente nocivo debe hacer parte de una comunidad indígena, ${ }^{63}$ mientras el factor territorial demanda la ocurrencia del hecho imputable dentro del territorio en el que habita la comunidad. ${ }^{64}$ Por su parte, el factor institucio-

deberán tomarse debidamente en consideración sus costumbres o su derecho consuetudinario. Dichos pueblos deberán tener el derecho de conservar sus costumbres e instituciones propias, siempre que estas no sean incompatibles con los derechos fundamentales definidos por el sistema jurídico nacional ni con los derechos humanos internacionalmente reconocidos. Siempre que sea necesario, deberán establecerse procedimientos para solucionar los conflictos que puedan surgir en la aplicación de este principio".

60 Lo cual, no obstante, no es una ordenanza taxativa, pues requiere un estudio ponderativo entre los valores jurídicos tutelados a partir de la defensa de las comunidades multiculturales existentes en Colombia, frente a los valores deprecados por el ordenamiento común. Es en este entendido que la Corte Constitucional colombiana, Sentencia T-397 de 29 de julio de 2016, M. P. Gabriel Eduardo Mendoza Martelo, para. 5.5.1 y 5.5.2, precisó: "Al fijar el alcance de este último enunciado normativo, la Corporación ha considerado, desde tempranos pronunciamientos, que si bien este se refiere a la Constitución y la ley como límites a la jurisdicción especial indígena, no lo es menos que la autonomía no puede ser restringida por cualquier disposición constitucional o legal, pues ello reduciría a un plano puramente retórico el principio de diversidad étnica y cultural [...] Así, entonces, se ha hecho énfasis en que los límites a la autonomía de las comunidades indígenas solo pueden ser aquellos que se refieran a lo verdaderamente intolerable desde el punto de vista de las garantías fundamentales, a partir de un consenso intercultural lo más amplio posible. Ello involucra, por ejemplo, el derecho a la vida (art. $11 \mathrm{CP}$ ), la prohibición de tortura (art. $12 \mathrm{CP}$ ) y esclavitud (art. $17 \mathrm{CP}$ ), y el principio de legalidad penal (art. $29 \mathrm{CP})^{\prime \prime}$. En el mismo sentido: Corte Constitucional de Colombia, Sentencia SU-510 de 18 de septiembre de 1998, M. P. Eduardo Cifuentes Muñoz, para. 49.

61 Corte Constitucional de Colombia, Sentencia T-617 de 5 de agosto de 2010, M. P. Luis Ernesto Vargas Silva, para. 12.3.

62 Corte Constitucional de Colombia, Sentencia T-397 de 29 de julio de 2016, M. P. Gabriel Eduardo Mendoza Martelo, para. 5.6.3; Corte Constitucional de Colombia, Sentencia T-975 de 18 de diciembre de 2014, M. P. Jorge Ignacio Pretelt, para. 4.4.2.12.

63 Frente a este aspecto, la Corte Constitucional colombiana, Sentencia T-975, cit., para. 4.4.2.12 y 5.2.1, consolida una serie de subreglas, que dependen de si el indígena incurre en una conducta sancionada solamente por el ordenamiento nacional, o bien incurre en una conducta sancionada tanto en la jurisdicción ordinaria como en la jurisdicción indígena. Para el primer caso, los jueces de la República son competentes para conocer del caso, no obstante, deberán analizar si el individuo imputado, al ser culturalmente distinto, entendía la ilicitud de su conducta. Por su parte, en el segundo caso, el juez deberá analizar: i) la conciencia étnica del sujeto y ii) el grado de aislamiento de la cultura a la que pertenece. Como bien observamos, ninguno de los supuestos radica en respuestas objetivas, $y$, por el contrario, exige al juez la determinación de conveniencia frente al indígena imputado en cuanto sea procesado y sancionado por el sistema jurídico nacional, o si corresponde a su comunidad juzgarlo y sancionarlo según sus normas y procedimientos.

64 Es imprescindible la aclaración de que bajo el término "ámbito territorial", la Corte Constitucional colombiana, Sentencia T-397, cit., para. 5.6.3., ha mencionado que "la noción de territorio no se agota en la acepción geográfica del término, sino que debe entenderse también como el ámbito donde la comunidad indígena despliega su cultura", por lo que el territorio abarca incluso el aspecto cultural, lo cual le otorga un efecto expansivo, "de modo que un hecho ocurrido por fuera de esos límites puede ser remitido a las autoridades indígenas por razones culturales". 
nal u orgánico hace referencia a la necesaria existencia de una institucionalidad dentro de la comunidad indígena, basada en un sistema de derecho propio constituido por los usos y las costumbres tradicionales y los procedimientos conocidos y aceptados en la comunidad.$^{65}$ Finalmente, el factor objetivo se centra en esclarecer "la naturaleza del sujeto o del bien jurídico afectado por una conducta punible, de manera que pueda determinarse si el interés del proceso es de la comunidad indígena o de la cultura mayoritaria". ${ }^{66}$

Por último, la Corte Constitucional colombiana, en la Sentencia T-002 de 2012, precisa los elementos orientadores que permiten definir la competencia, a saber: i) las culturas involucradas, ii) el grado de aislamiento o integración del sujeto frente a la cultura mayoritaria y iii) la afectación del individuo frente a la sanción. Estos parámetros deberán ser evaluados dentro de los límites de la equidad, la razonabilidad y la sana crítica.

Por su parte, Carnevali precisa tres subreglas categoriales por niveles que deben superarse sucesivamente para determinar la existencia de una cultural defences o culturally motivated crimes, ${ }^{67}$ a saber: i) la determinación de los motivos psíquicos que permiten dilucidar las motivaciones culturales tras su obrar, analizando con esto el ejercicio de "códigos culturales que lo condicionan dentro de un determinado contexto"; ii) la coincidencia cultural entre el obrar del sujeto y el grupo de pertenencia; y iii) la "relación antinómica entre la cultura de pertenencia y la cultura del lugar de residencia", que permita otorgar eximentes o atenuantes al delito culturalmente motivado. ${ }^{68}$

En todo caso, al ser la determinación de estos criterios fuente de inagotables debates, uno de los elementos que genera mayor controversia para aceptar -más allá del hecho delictivo- una jurisdicción especial que acoja procesos

$65 \quad$ Este elemento requiere, según la Corte colombiana, tanto que "exista un poder de coerción social por parte de las autoridades tradicionales", así como "un concepto genérico de nocividad social". Aunado lo anterior, dicha institucionalidad debe lograr desarrollar tres criterios de interpretación: "La Institucionalidad es presupuesto esencial para la eficacia del debido proceso en beneficio del acusado; la conservación de las costumbres e instrumentos ancestrales en materia de resolución de conflictos y la satisfacción de los derechos de las víctimas" (Corte Constitucional de Colombia, Sentencia T-397, cit., para. 5.6.3; Corte Constitucional de Colombia, Sentencia T-975, cit., para. 4.4.2.12).

66 En esta medida caben tres posibilidades, que el bien jurídico afectado, o su titular, pertenecen a una comunidad indígena, o que estos pertenecen exclusivamente a la cultura mayoritaria, o finalmente encuentra una pertenecía a ambas. Así las cosas, el elemento objetivo precisa en el primer supuesto la competencia de la jurisdicción especial indígena, mientras en el segundo de la justicia ordinaria. "Sin embargo, en el evento (iii), el elemento objetivo no resulta determinante para definir la competencia. La decisión del juez deberá pasar por la verificación de todos los elementos del caso concreto y por los demás factores que definen la competencia de las autoridades de los pueblos aborígenes" (Corte Constitucional de Colombia, Sentencia T-617, cit., para. 16.1.7).

67 En la misma dirección, la antropóloga Cristina Garrido en el proceso del Tribunal de Juicio Oral de Calama, Caso Andrés Arsenio, op. cit., pp. 27-33, apoya sus tesis para determinar la existencia de un proceso penal de connotación cultural, en la medida que el imputado posea una i) calidad colectiva-cultural como la comunidad étnica, ii) posea una relación con el paisaje cultural y iii) el objeto delictual perseguido por el imputado sostenga una relación cultural.

68 Carnevali, “El multiculturalismo”, op. cit., pp. 24-25. 
basados en cultural defences o culturally motivated crimes, es la concerniente al exigido respeto indefectible frente a los derechos humanos. ${ }^{69}$ Así, en primera instancia, esto se debe a que los derechos humanos son un cuerpo de instrumentos internacionales que abarca una gran cantidad de estándares jurídicos, los cuales en su acumulación consolidan una visión particular de la vida en sociedad basada en la dignidad humana, ${ }^{70}$ lo que no en pocas ocasiones puede acarrear diversos tropiezos frente a la cosmovisión de una comunidad culturalmente independiente $y$, si se quiere, no adoctrinada a través de la corriente occidental de estos cuerpos jurídicos. ${ }^{71}$

En segunda medida, y aun superándose el carácter abarcador de los "derechos humanos", no podemos suponer que estas fronteras jurídicas pueden ser aplicables a todas las particulares culturas existentes en la humanidad, por lo que se requerirá un examen acucioso en cada una de ellas, frente a lo cual, tras su ponderación, se establecerían nuevos límites, necesariamente diferentes en cada jurisdicción, lo que da como resultado la ausencia de una regla objetiva para concebir los criterios fácticos de la conducta y psicológicos del imputado (actus reus y mens rea) para resolver el dilema cultural, sea esto en sede de antijuridicidad, o bien de culpabilidad.

Así las cosas, y sin temor a esquivar nuestro objetivo de delimitar las pautas básicas de un modelo coherente frente a la multiculturalidad (incorporación de estándares internacionales, reconocimiento y apoyo político y financiero del Estado, implementación de jurisdicciones especiales), lo cierto es que este es imposible de cumplir, tanto por los supuestos en que hace inviable el reconocimiento cultural y la violación de los derechos humanos (y no por ello un motivo carente de un argumento cultural), como imposible es delimitar las dimensiones de la cultura humana, esto es, del entendimiento del ser como un reflejo de una comunidad de costumbres, impermeables por reglas y categorías, y aun así productoras de culturas disidentes de la generalidad.

69 Al respecto expone el penalista español Jesús Silva Sánchez, “Reflexiones sobre las bases de la Política Criminal", Revista de Derecho de la Universidad Católica del Norte, 8 (2001), p. 196, que: "existen mínimos que una sociedad no puede renunciar - tesis universalista - y que hallan su basamento en los derechos fundamentales, sobre los cuales no cabe oponer posturas sustentadas en consensos culturales".

70 En este sentido, la jurista Catherine Dupré, The Age of Dignity, Human Rights and Constitutionalism in Europe, Oxford, Hart, 2015, p. 4, precisa: "Human dignity is a notoriously difficult concept to grasp and to define, inddeed understanding it si arguably such a scholarly challenge that the best we can hope for might be a fragmented and partial picture. At a complex crossroads of many disciplines, incluiding history of ideas, philosophy, theology, sociology, political theory and law, we might have to contend with the kaleidoscopic picture typically constructed by edited collectios of essays. The global appeal and uses of human dignity call for aglobal perspective, and a number of studies have confirmed its abundant uses, without always succeeding in fully illuminating its development", por lo que desde una postura armónica e integral del contenido caleidoscópico de la dignidad podemos concluir que no es un juego de "todo y nada", sino, por el contrario, de "todo y más".

71 Como bien lo expresa María Josefina Martínez, “Recensión García Vitor, Enrique: Diversidad cultural y Derecho Penal", Revista Nueva Doctrina Penal de la Universidad Nacional del Litoral (1996), p. 811, en América Latina no fueron los ciudadanos los que decidieron fundar el Estado, sino que más bien fue el Estado el que fundó la ciudadanía conforme a principios republicanos propios de las teorías de la ilustración, excluyendo en la conformación del estado-nación, desde el primer momento, otras formas de organización autóctona, que debieron adaptarse para no desaparecer. Véase también Carnevali, “El multiculturalismo", op. cit., pp. 5-6. 
Consideramos, pues, que la autodeterminación de las comunidades, reflejada en jurisdicciones especiales, puede ser lo más cercano al optimus buscado, pues no habrá ningún tribunal más capacitado para determinar el alcance de la defensa soportada por libelos culturales, esto, claro, en el marco de un rigor homogeneizante del paradigma de los derechos humanos.

Finalmente, si bien es cierto esta primera categoría trae consigo más cuestionamientos que indubitables exactitudes, no es menos cierto precisar que un relacionamiento utópico de jurisdicciones penales respetuosas de las particulares perspectivas sociales, sin aprovechamientos jurídicos y tratando en todos los casos de sostener una constructiva coherencia frente a la dignidad de cada ser humano, es un escenario al que debería arribarse en un verdadero respeto de la multiculturalidad, pues en esto se basa gran parte de las creencias jurídicas que postulamos como contemporáneas, así como en los pilares filosóficos de la libertad, igualdad y fraternidad de la que hacen parte nuestros Estados y las organizaciones internacionales a las que pertenecen.

\subsection{Sistema medianamente coherente}

Este sistema de tratamiento de los delitos derivados de motivos culturales debe reflejar, en esencia, una posición criminológica hegemonizante reducida, esto es, que proyecte no solo una respuesta móvil dependiendo del grado de lesiones ocasionadas al sistema jurídico, sino también que la conducta, al estar consagrada en el marco de las cultural defences o culturally motivated crimes, no puede partir de ser señalada como una acción per se antijurídica.

Para explicar a profundidad este ítem, hemos de basarnos en lo que llamaremos la opción válvula, cuyo fundamento radica en la categorización del hecho delictual a través de su consagración antijurídica formal o material. En tal medida, si el comportamiento recae en la antijuridicidad formal, esto es, cuando un hecho es contrario al ordenamiento jurídico, ${ }^{72}$ la reacción inmediata de la opción válvula será tratar dicha conducta en la teoría del delito en la sede de eximentes provenientes de la tipicidad; por su parte, al contemplar que la conducta imprime una antijuridicidad material, el tratamiento en la teoría del delito para estos casos se redireccionará a la sede de la antijuridicidad, a fin de establecer con la ponderación de valores jurídicos en juego (libertad de conciencia vs. bien jurídico afectado por el comportamiento) el grado de atenuación de la responsabilidad.

En efecto, lo que se propone es la integración en la teoría del delito de un análisis más conducente al entendimiento subjetivo de la otredad en términos

72 Mauricio Alfredo Rettig Espinoza, “Desarrollo previsible de la relación entre la antijuridicidad y la culpabilidad", Revista de Derecho 22 (2) (2009), p. 186. 
criminológicos, esto es, el grado de daño social existente en un acto sostenido por razones culturales. Así, de este dependerá la sede en la que se tramitará la conducta motivada culturalmente.

Con todo, cuando se trate de una conducta antijurídica de naturaleza formal, tratada-como lo advertíamos- en sede de tipicidad a través de lo que denominaremos "error de tipo culturalmente condicionado", puede estar sustentada en dos opciones posibles: i) en la corrección político-criminal de adecuación social, siempre que, producto del finalismo (de carácter real-normativo), al derecho penal se le demanda tanto el respeto de la estructura lógico-objetiva de la regulación jurídica, como el cumplimiento de la función y de los fines del derecho penal sin contradicciones y conforme a los valores a que se orienta, por lo que dicho componente normativo en el campo de lo injusto desempeña la función político-criminal de trazar un límite entre lo penalmente relevante y aquello irrelevante ${ }^{73}$ (razón por lo que también se lo conoce como "principio de insignificancia") $;^{74} \mathrm{o}$ bien en la ii) ausencia de la creación de la base de imputación objetiva, esto es, la falta de creación de un riesgo, ${ }^{75}$ dotándolo de un carácter jurídicamente legítimo que permita inviabilizar la imputación típica. ${ }^{76}$

En tal medida, esta solución criminológica permite dotar de amplitud interpretativa un hecho que bien podría estar permitido dentro del ordenamiento penal el cual, por tanto, no sería considerado prima facie típico, lo cual hace que

73 Como contundentemente lo resalta Luis Gracia Martín, “La 'adecuación social' como 'el cierre normativo' de lo injusto en el finalismo y el abismo sistemático que la distancia de los criterios de la doctrina de la imputación objetiva", Revista Derecho penal, Constitución y Derechos (2013), p. 233, realizando un análisis del desarrollo de la adecuación social en la teoría del delito y los estudios de Welzel, precisa "la 'idea' de la 'adecuación social' habría sido originalmente formulada e introducida en la teoría general del delito por Welzel en sus Studien zum System des Strafrechts, de 1939. Ya aquí, la adecuación social se muestra como un criterio esencialmente normativo, pues la misma opera ante todo como criterio de valoración de la acción en el ámbito de lo injusto. En una primera aproximación, solo pueden ser constitutivas de lo injusto y estar comprendidas en los tipos penales acciones 'socialmente inadecuadas', es decir, acciones 'que caen fuera gravemente del orden de la vida social que se ha formado históricamente'. Por ello, y a la inversa, tienen que quedar excluidas de lo injusto todas aquellas acciones que pueden valorarse como 'socialmente adecuadas'. 'Acciones socialmente adecuadas son todas las actividades en que se realiza la vida de la comunidad de acuerdo con su propio orden históricamente condicionado'. Dicho de otro modo: socialmente adecuada es toda acción 'que se desenvuelve funcionalmente dentro del que históricamente se ha constituido como el orden de la vida común de un pueblo"',.

74 Dolores Aguad, Natalia Bazan, Daniela Bianciotti, Milagros Gorgas y Berenice Olmedo, "La regulación provincial del principio de oportunidad. Sistematización comparativa de las legislaciones provinciales que receptan institutos de oportunidad procesal", Academia Nacional de Derecho y Ciencias Sociales de Córdoba, Instituto de Ciencias Penales, 2011, p. 5-6, en http://www.acaderc.org.ar/doctrina/articulos/la-regulacion-provincial-de-principio-de/at_download/file, fecha de consulta: 4 de julio de 2021.

75 La conexión entre la imputación objetiva y el riesgo antijurídico se explica en la medida que se constate la existencia de creación o incremento de un riesgo que genere una producción de resultado típico. Así las cosas, la generación de dicho riesgo violenta el deber objetivo de cuidado, el cual, no obstante, debe constatar si materialmente vulnera el fin de protección de la norma o el ámbito de protección, pues de esto depende el alcance del tipo (Claus Roxin, Derecho penal parte general, Tomo I, Fundamentos de la estructura de la teoría del delito, Madrid, Civitas, 1997, pp. 364-365).

76 En este sentido, Gimbernat Ordeig, ¿Qué es la imputación objetiva?, Estudios de Derecho penal, 3 ed., Madrid, Tecnos, 1990, p. 215, precisa de forma adecuada que "como en los casos que estamos examinando existe un comportamiento doloso causante de un resultado típico y concurren, con ello, todos los elementos -expresamente previstos por la Ley- que la doctrina dominante atribuye a la tipicidad del delito doloso, de ahí que la única posibilidad de fundamentar la atipicidad de esas conductas sea la de demostrar que el riesgo permitido desempeña un papel, no solo en el tipo de los delitos imprudentes, sino también en el de los dolosos". 
las motivaciones culturales hagan parte desde el inicio analítico de la teoría del delito como factores de reconocimiento social, pues en palabras de Gracia Martín "las acciones socialmente adecuadas estarán excluidas de los tipos de lo injusto, aunque se produzcan lesiones de bienes jurídicos a consecuencia de ellas y aunque puedan ser subsumidas en ellos de acuerdo con criterios causales y con su tenor literal". ${ }^{77}$ En tal sentido, de aquí se desprende parte de la "mediana coherencia" de este modelo.

Cabe resaltar que esta incursión de la cultural defence o culturally motivated crimes en los errores tipo tiene un alto grado de argumentación en lo que Silva Sánchez ha denominado "Derecho penal de la globalización", el cual, aunado a la transformación procesal del derecho penal, acude también a la flexibilización del principio de legalidad material, pues la exigencia globalizadora del contexto demanda un debilitamiento de la garantía de la taxatividad de los tipos, y con ello, su acercamiento a un grado más tolerante de adecuación social, ${ }^{78}$ o en igual medida, del vislumbramiento de un riesgo atenuado en una sociedad multicultural. ${ }^{79}$

Ahora bien, tratándose de conductas antijurídicas materialmente, si bien podrían también enmarcarse en la solución supra expuesta, estas -de mejor fórmulapueden tener una solución basada en la ponderación de los valores en juego, ello debido a que la conducta motivada culturalmente es, por sí misma, un ejercicio legítimo de un derecho, en este caso, la libertad de conciencia, el cual no puede ser negado absolutamente aun cuando este haya implicado - paralelamente- resultados lesivos al ordenamiento jurídico. ${ }^{80}$ De tal manera, aunque no pueda considerarse una fórmula objetiva de solución, por cuanto diversos son los intereses en juego, sí se puede inferir que un tratamiento criminológico que soporte el reproche penal en un análisis que pondera a la motivación cultural como un valor -no exiguo- que exige una modulación de razonabilidad a la antijuridicidad, es en sí misma una adecuación a la propia teoría del delito.

No obstante, en tanto es claro que deben definirse qué reglas seguir en la ponderación de valores (probablemente una mezcla entre los factores personal y objetivo $^{81} \mathrm{y}$ el grado de aislamiento o integración del sujeto, ${ }^{82}$ establecidos por la

77 Luis Gracia Martín, “La estructura dogmática y la función político criminal de la 'adecuación social' como 'cierre normativo' de lo injusto", Revista Argentina de Derecho Penal y Procesal Penal 5 (2012), en https:// ar.ijeditores.com/pop.php?option=articulo\&Hash=aacb36002b99246b6d56067ce2596819, fecha de consulta: 05 de junio de 2021.

78 Para observar un ejemplo en el conflicto armado y la flexibilización criminológica en la infancia y adolescencia, véase Juliana Díaz, "La aleatoriedad de la condición de víctimas y/o victimarios de la infancia y adolescencia en el conflicto armado colombiano", CES Derecho 10 (2) (2019), p. 581.

79 Jesús María Silva Sánchez, La expansión del Derecho, op. cit., pp. 100, 101.

80 Véase Faundes, "Derecho fundamental", op. cit. pp. 67-70; desde un punto de vista alterno, pero no contrario, señala Rafael Alcácer Guirao, "Diversidad cultural, intolerancia y derecho penal”, Revista Electrónica de Ciencia Penal y Criminología 18-11 (2016), p. 28, que la prohibición será proporcionada, siempre "que no disuada en

81 Corte Constitucional de Colombia, Sentencia T-397, cit., para. 5.6.3; Corte Constitucional de Colombia, Sentencia T-975, cit., para. 4.4.2.12.

82 Corte Constitucional de Colombia, Sentencia T-002 de 11 de enero de 2012, M. P. Juan Carlos Henao, para. 1.4.a. 
Corte Constitucional colombiana, más la coincidencia cultural entre el obrar del sujeto y el grupo de pertenencia ${ }^{83}$ y la insuperabilidad de su actuación ${ }^{84} \mathrm{en-}$ tre otras), así como los presupuestos que distingan claramente qué constituye una conducta antijurídica formal y qué una de naturaleza material (funcionamiento de la opción válvula), y establecer si existe la posibilidad de justificación de antijuridicidad, o por el contrario, solo la atenuación de esta, por otro lado, tampoco es posible negar que este mecanismo abandona de forma semiarmoniosa, desde el constructo penal hegemónico, actuaciones que considera lesivas al ordenamiento jurídico, pero que no por ello las señala per se como antijurídicas, lo cual es un avance (figura 1).

\section{Figura 1. Posicionamiento de la cultural defences/culturally motivated crimes a partir de la opción válvula}

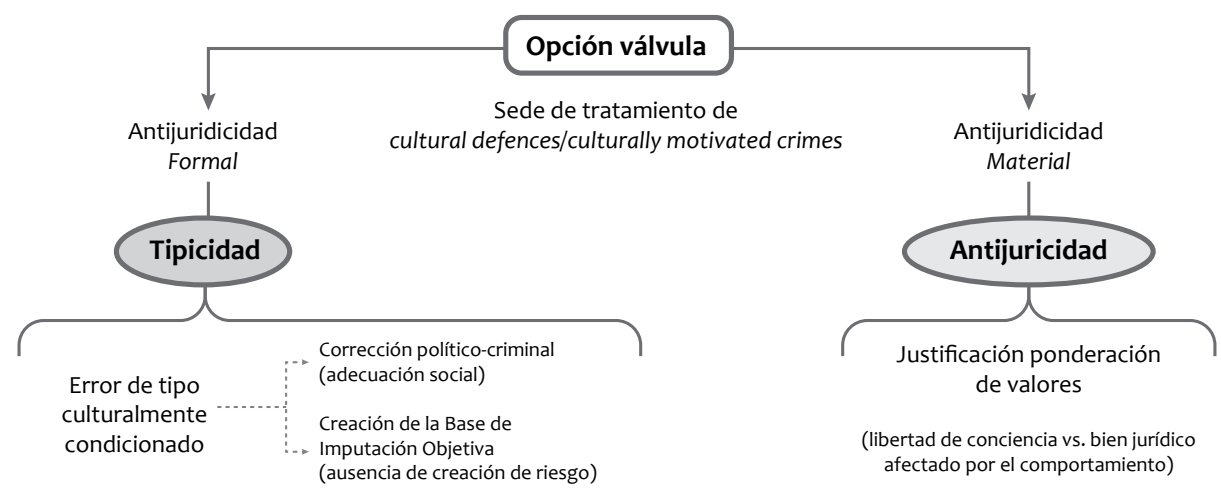

Fuente: elaboración propia.

\subsection{Sistema de escasa coherencia}

Consideramos que un modelo de escasa coherencia es aquel que deriva la resolución criminológica de las conductas motivadas culturalmente en sede de culpabilidad, esto es, cuando la cultural defence o culturally motivated crimes genera una atenuación o exclusión de la sanción como una medida de ultima ratio, solo después de considerar la conducta como típica y antijurídica. Así las cosas, se elude en todo o parte el reproche jurisdiccional por la ausencia de conocimiento e incluso comprensión de los valores vulnerados del ordenamiento jurídico, ${ }^{85}$ razones que poco o nada abordan el valor de las lesiones generadas por la conducta, el valor del ejercicio cultural, y el tratamiento hegemónico criminal que se impone, más aún cuando se posibilita una relación cercana a la inimputabilidad por falta de capacidad.

\footnotetext{
83 Carnevali, "El multiculturalismo", op. cit., pp. 24-25.

84 Cercanas a las del estado de necesidad justificante agresivo, estableciéndose criterios para determinar el grado de "insuperabilidad" de las motivaciones culturales, aunado al grado de vulneración del acto dañoso, tanto para la víctima como para el ordenamiento jurídico. Véase Jairo Lucero, “La exculpación”, op. cit., p. 334. 
En efecto, esta fórmula puede implicar dos supuestos: i) la inimputabilidad del actor, o ii) la atenuación de culpabilidad sustentada en el error de prohibición.

El primero de estos (más cercano a un modelo incoherente) postula dos condiciones para la inimputabilidad por motivaciones culturales: la "anomalía psíquica" o la "alteración en la percepción". Así, o bien se asimila a los constructos culturales como un tipo de incapacidad mental que impide el conocimiento o la comprensión del ordenamiento jurídico punitivo ${ }^{86}$ (cercano al insanity), o, por otro lado, se asimilan como un supuesto de alteración de la realidad (cercano a la diminished capacity), cuyo conflicto le impide al actor entender la ilicitud de sus actos..$^{87}$ Como quiera, ambas imprimen un sello etnocentrista ${ }^{88}$ en la aplicación de la teoría del delito, y señalan los motivos culturales como un razonamiento "subdesarrollado" 89 que debe ser, como excepción, no reprochado.

Por su parte, la fórmula del error de prohibición culturalmente condicionado (cercano al mistake of act) se configura a partir del i) desconocimiento de la antijuridicidad de su conducta ii) producto de las condiciones diferenciadas (culturalmente motivadas) que le impiden interiorizar dichas "prohibiciones" esgrimidas en el ordenamiento jurídico. ${ }^{90}$ Ahora bien, permite sostener dos supuestos en los que actúa el error: la falta de conocimiento o la falta de comprensión. A pesar de parecer sinónimos, el conocimiento se destina en exclusivo a los casos en los que existe en el actor ausencia de conocimiento de que su conducta vulnera una norma jurídica, esto es, que es un ilícito (es decir, típico y antijurídico), o bien existe una probabilidad alta de su conocimiento; ${ }^{91}$ por su parte, la comprensión se cimenta en que el conocimiento no es suficiente para declarar culpable a un actor motivado culturalmente, sino que también debe exigirse un examen frente al grado de comprensión que este actor tiene, ${ }^{92}$ lo cual, cuanto más trata de esgrimir una mayor garantía, la hace más subjetiva, pudiendo

86 Al respecto Monge Fernández, El extranjero, op. cit., 2008, p. 71, señala que "los sujetos no actúan movidos porque les obligue su conciencia, sino en la mayoría de los casos guiados por la tradición, lo que no encaja en el concepto de enfermedad mental", señalando posteriormente que las acciones derivadas de la "exaltación fanática" (cercano a provocation excuse) pueden perfectamente acarrear estados de justificación devenidos de "condicionamientos de carácter exógeno ambiental o sociocultural", y no del orden de un padecimiento de una patología mental.

87 Lo cual, no lejano al orden de estabilidad psicológica, José Cerezo Mir, “La regulación del error de prohibición culturalmente condicionado en el Código Penal peruano", en Universitas Vitae: homenaje a Ruperto Núñez Barbero, Salamanca, Universidad de Salamanca, 2008, pp. 101-108, las considera una asimilación in malam partem a la realidad vivida y sentida por el actor motivado por razones culturales, pues ello no solo desvirtúa a la cultura como una percepción errónea de la normalidad, sino también que esta es de carácter individual, y no producto de una cosmovisión construida por un colectivo. Véase Adela Asua Batarrita, “Criminología y multiculturalismo. Medidas internacionales y propuestas de tratamiento jurídico para la erradicación de la mutilación genital femenina", Cuaderno del Instituto Vasco de Criminología 18 (2004), p. 84.

88 Cisneros, Derecho penal, op. cit., pp. 285, 302.

89 Cerezo, "La regulación del error", op. cit., p. 107.

90 De ahí el nombre del tipo de "error".

91 Verbigracia, si el actor se relaciona con las normas jurídicas, por tanto, difícilmente desconoce la ilicitud de su conducta, o cuando existe un "conocimiento potencial" desprendido del mínimo esfuerzo de comprender que su conducta es prohibida. Véase María Maqueda Abreu y Patricia Laurenzo Copello, El Derecho penal en casos. Parte general. Teoría y Práctica, Valencia, Tirant lo Blanca, 2017, p. 286. 
incluso confundirse como un mecanismo para cobijar al actor en una suerte de incapacidad de comprensión (cercana a la inimputabilidad)..$^{93}$

Si bien es claro que el error de prohibición culturalmente condicionado es una mejor fórmula -"criminológicamente hablando"- para la adecuación del sistema de la teoría del delito a las nuevas realidades derivadas de la multiculturalidad en el marco de la globalización y la diáspora de movilidad poblacional -o bien, es más coherente que el tratamiento de inimputabilidad-, no se debe perder de vista que esta sigue siendo una respuesta cuasi exculpatoria, de ultima ratio, frente a conductas culturalmente motivadas, siendo fácilmente posible que el o la operadora judicial no asuma el error de prohibición, lo que deriva en la aplicación clásica de la teoría del delito. Como quiera, es más difícil deshacer o mellar la responsabilidad en la última etapa de análisis criminológico después de considerarlo típico y antijurídico, que hacerlo antes de asignar a la conducta y actor dichas cargas (figura 2).

\section{Figura 2. Nivel de coherencia en el tratamiento de cultural defences/culturally motivated crimes en sede de culpabilidad}

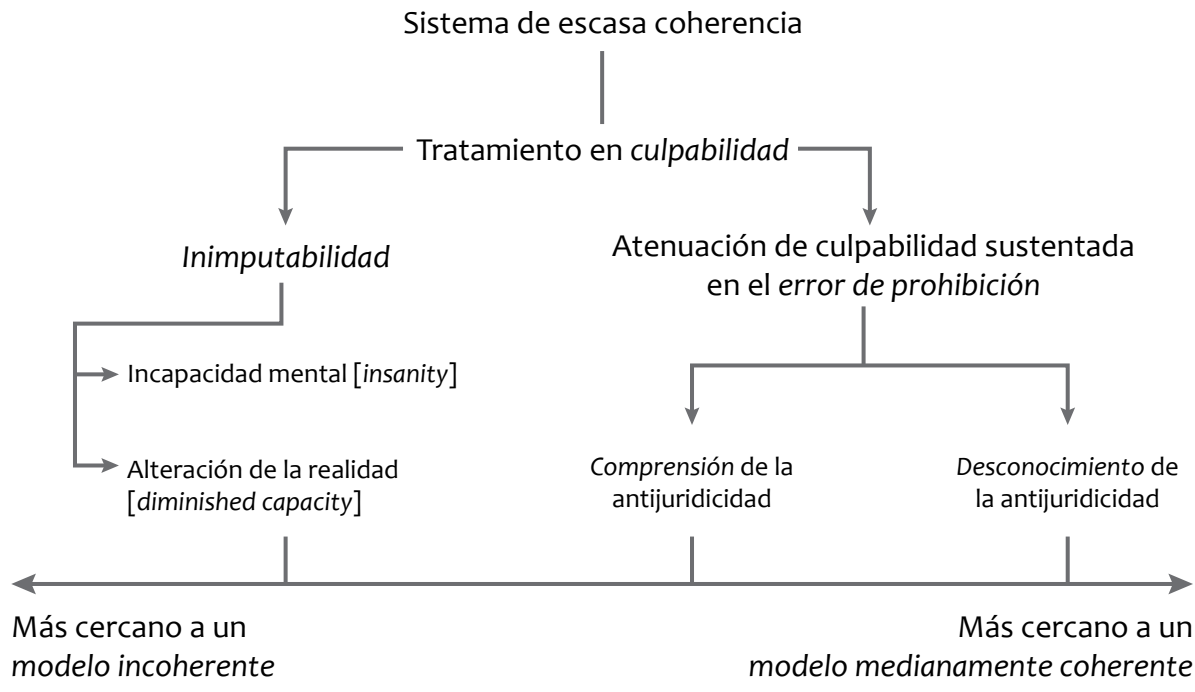

Fuente: elaboración propia.

93 El caso insigne es el Código Penal peruano que, deseando articular los postulados de Zaffaroni, abarcó en el mismo ámbito tanto el llamado "error de comprensión culturalmente condicionado", el cual se ocasiona cuando no se "comprende el carácter delictuoso de su acto o [bien se] determina de acuerdo a esa comprensión, será eximido de responsabilidad" (art. 15), y la "inimputabilidad" producto de la ausencia de la "facultad de comprender el carácter delictuoso de su acto o para determinarse según esta comprensión" (art. 20.1). Véase al respecto José Hurtado Pozo, "Derecho penal y diferencias culturales: el caso peruano", Derecho penal y Criminología 29-96 (2008), p. 71; Cisneros, Derecho penal, op. cit., p. 284. Iván Meini, Imputación y responsabilidad penal. Ensayos de Derecho penal, Lima, Ara Editores, 2012, p. 282, concluye que el ordenamiento peruano en cuanto conductas condicionadas por la cultura "regulan supuestos de inimputabilidad y no de error". Similar postura podemos encontrarla en los códigos penales colombiano (arts. 33 y 96.3) y boliviano (art. 17.5). 


\subsection{Sistema de nula coherencia}

Como bien se atisba por su denominación, este sistema hace un ejercicio hermético de formalismo frente a las instituciones jurídico-penales establecidas en la teoría del delito, lo que genera un riguroso resultado derivado de la consagración típica del delito y el daño social derivado de la antijuridicidad. Así las cosas, tampoco en sede de culpabilidad tendría cabida una justificación a partir del error de prohibición, dándole al resultado judicial una escasa coherencia con los instrumentos internacionales que demandan un reconocimiento a las diversas expresiones culturales existentes en una sociedad, y de estas, un tratamiento diferencial, también en el espacio penal.

\section{Encrucijadas ante nuevos panoramas}

Al final de este recorrido no podemos obviar algunos de los más serios cuestionamientos frente a la aplicabilidad de la cultural defences o culturally motivated crimes que, con base en una filosofía garantista, promueve el replanteamiento de las instituciones penales de la teoría del delito para asimilar constructos sociales que, si bien pueden atentar contra valores jurídicos de una mayoría social, requieren un tratamiento diferencial.

En esta medida es que podemos centrar estas reflexiones en dos principales encrucijadas:

- ¿Las cultural defences o culturally motivated crimes son aplicables solo hacia comunidades indígenas o también a grupos sociales con connotaciones culturales autónomas?

La importancia de dirimir esta problemática se centra en la medición de la expansión de esta institución criminológica a otros sectores sociales que demandan una racionalidad judicial que posea un entendimiento amplio de diversas cosmovisiones que sustentan el accionar de algunas comunidades fuera de la colectividad mayoritaria. Este es el caso de las comunidades campesinas que por largos años han requerido el reconocimiento de una identidad propia a nivel internacional. ${ }^{94}$ Así, ¿es en esta medida necesario brindar a dicha colectividad una consideración racional punitiva acorde con sus construcciones culturales?, ¿el Convenio 169 cumple una función expansiva de garantías a

94 Un claro ejemplo de ello es la Resolución A/HRC/39/L.16 del Consejo de Derechos Humanos de las Naciones Unidas relativa a la "Declaración de las Naciones Unidas sobre los derechos de los campesinos y de otras personas que trabajan en las zonas rurales" del 26 de septiembre de 2018, instrumento que posibilita el reconocimiento identitario de las colectividades agrarias con base en su función social, económica y cultural devenida de la producción rural. En este sentido, Sergio Schneider y Fabio Escher, La construcción del concepto de agricultura familiar en América Latina, Chile, FAO, 2012, pp. 12-13, precisan desde el término agricultura familiar la consolidación de "una categoría social y una construcción política reciente, que hace referencia a modelos o sistemas económicos existentes en el medio rural, categorizados bajo distintos nombres y que busca darles una nueva connotación social, simbólica y de identidad". 
favor de otras culturas e identidades frente a las prerrogativas consagradas a las comunidades indígenas y tribales?

Como respuesta mediata a ello, la sentencia Andrés Arsenio Plaza, del Tribunal de Juicio Oral en lo Penal de Calama (Chile) -reseñada supra-, da cuenta de ciertos requisitos que estas comunidades, desde un punto de vista antropológico, deben tener para configurar en sí mismas un constructo no solo ajeno a la visión cultural mayoritaria, sino para autenticar la existencia de un sostén cultural propio, coherente e individualizable. De tal forma, es imprescindible un trasfondo cultural, constituido por la i) movilidad espacial y el paisaje cultural -relación del sujeto imputado con un contexto que guarda identidad cultural-; ii) los vínculos rituales del colectivo y su territorio -haciendo hincapié en la necesaria conexión de todos los individuos con los comportamientos culturales que distinguen su colectividad, haciendo todos parte de un solo sentir y práctica cultural-; iii) la organización social fundamentada en la perspectiva cultural. ${ }^{95}$

Podríamos en tanto concluir que, al sobrepasar estas condiciones mínimas, la cultural defences o culturally motivated crimes debe también cubrir colectividades por fuera de una colectividad indígena. Con todo, no debe perderse de vista que es imposible buscar respuestas objetivas y concretas en la caracterización cultural de un individuo o una comunidad, pues su estudio y regulación siempre se encontrarán limitados por el paradigma hegemónico desde el que se encuentra el investigador o juzgador, decisión que, en sí misma, se verá superada por el infinito contenido de los elementos del objeto y sujeto de estudio.

- ¿Qué tipo de hechos típicos son admisibles en las cultural defences o culturally motivated crimes?

Este interrogante se dirige a confrontar qué tipo de delitos pueden proveer una justificación basada en fundamentos culturales (léase en el sentido amplio de la palabra, desde la tipicidad, antijuridicidad o culpabilidad), o, por el contrario, si todos los hechos delictivos pueden servirse de este estudio. A partir de este cuestionamiento debemos remitirnos a que la determinación de los tipos penales depende de la valoración de la lesión a un cierto bien jurídico tutelado, lo cual dependerá de la sociedad de que se trate. Si bien con esto no queremos hacer alusión a nuestra fórmula válvula que remite el tratamiento criminológico dependiendo de la naturaleza formal o material de la antijuridicidad, el cuestionamiento más bien hace referencia a reflexionar sobre qué valores son realmente impenetrables en una sociedad que no admitan justificaciones asentadas en razones culturales, lo cual, de llegar a plantearse taxativamente, puede llevarnos a una discusión un tanto más inquietante: ¿la consagración de valores a ciertas manifestaciones culturales no implica -como ya lo mencionamos frente a las tesis comunitaristas ${ }^{96}$ - la apertura a segregaciones culturales, dependientes de deliberaciones políticas, más que judiciales?

95 Tribunal de Juicio Oral de Calama, Caso Andrés Arsenio, op. cit., pp. 27, 29, 33, 35, 36.

96 Carnevali, “El multiculturalismo", op. cit., p. 21. 
La salida no prolija a esta discusión recae, tanto en acertar en modelos lo más coherentes posibles en el tratamiento de conductas culturalmente motivadas, así como de acentuar en los contextos de razonamiento judicial una visión integral pro homine en las decisiones, esto es, provocando el ejercicio de decisiones multinivel ${ }^{97}$ que impidan generar completas discriminaciones hacia perspectivas culturales de alta carga de valor, para generar, incluso, instancias de deliberación colegiada que mellen el chance de una "adecuación social" desde el derecho penal con tintes etnocéntricos.

Es necesario reconocer que las muestras de certeza retratadas frente a la compatibilización del multiculturalismo en la teoría del delito son más difusas que concretas, pero ello denota en igual sentido la naturaleza misma de una ciudadanía multicultural; como bien asimila Kymlicka, el fenómeno globalizante ha hecho que el mito del Estado culturalmente homogéneo sea aún más irreal. ${ }^{98}$ En tal medida supervive una gran demanda por la existencia de un derecho penal supracultural, ${ }^{99}$ que requiere mínimas reglas de intercomunicación con las instituciones jurisdiccionales comunes del colectivo mayoritario, así como también con los sistemas regionales y universales de derechos humanos, hecho que implica la necesidad de una plataforma jurídica que armonice lo sustancialmente diverso a través de reglas de razonamiento comunes. La gran duda de esta discusión es si a través de la búsqueda de este objetivo -probablemente utópico- se inspira, como rescata Vogel, un derecho penal globalizado que gradualmente se aparta de los principios jurídico-penales tradicionales, ${ }^{100}$ lo que Prittwitz lo categoriza como una "dolorosa erosión de nuestra común herencia cultural", en cuyo proceso de adaptación a las nuevas realidades, como lo es la incorporación del constructo cultural al juzgamiento penal, pueden "perderse estándares de derechos y -paradójicamente- peculiaridades de las distintas culturas jurídicas" ${ }^{101}$

La última palabra la sostendrá el nivel de fortaleza que cada sociedad soporte ante la protección de la multiculturalidad como herencia en peligro, la cual puede difuminarse en su choque con estructuras jurídico-penales que sancionen la posibilidad de vislumbrar diversas realidades, donde el ideal es un diálogo amplio constitucional, y, por qué no, como lo afirma Michele Carducci, que nos derive a un "constitucionalismo de la alteridad", ${ }^{102}$ y su correspondiente criminología de la multiculturalidad.

97 Carducci, “El multiculturalismo", op. cit., pp. 87-89. Véase Jairo Lucero, “El juez multinivel y la transversalidad de garantías. Un acercamiento a los escenarios fácticos en América y Europa", Opinión Jurídica 20-41 (2021), pp. 71-99.

98 Will Kymlicka, Ciudadanía multicultural, Barcelona, Paidós, 1996, pp. 22-23.

99 Carnevali, “El multiculturalismo", op. cit., p. 20.

100 Vogel, "Derecho penal", op. cit., p. 113.

101 Cornelius Prittwitz, "Skizzen zu Strafrecht und Kriminalpolitik in Zeiten der Globalisierung", en Strafrechtsprobleme an der Jahrtausendwende, Alemania, Deutsch-Griechisches, 2000, p. 164. Véase también Emiliano Borja Jiménez, "Justicia penal preventiva y Derecho penal de la globalización: proyecciones en el ámbito del terrorismo", ADPCP LXX (2017), pp. 38-39.

102 Carducci, “El multiculturalismo", op. cit., pp. 83-91. 


\section{Palabras finales ante un mundo multipolar}

Si bien existe una amplia gama de críticas respecto al tratamiento penal benigno basado en condiciones culturales, esto por cuanto puede implicar desprotecciones injustificables si a priori no se desarrolla un juicio ponderativo de los valores jurídicos en juego, también es cierto que se extiende una gran red de garantías sostenidas en instrumentos internacionales y constitucionales que protegen la autodeterminación y la libertad de conciencia (especialmente tratándose de comunidades indígenas y tribales), cuya tutela exige una modulación -o incluso un entendimiento alternativo- a los fines preventivogenerales $^{103}$ de la pena.

Por tanto, es necesario, primero, el reconocimiento de los diferentes sistemas de tratamiento penal frente a las conductas motivadas por razones culturales, y segundo, la interiorización de la necesidad de alcanzar un modelo criminológico coherente o, como mínimo, medianamente coherente en aras de cumplir de manera armónica el marco normativo garantista dispuesto en una realidad multicultural.

\section{Bibliografía}

Aguad, Dolores, Natalia Bazan, Daniela Bianciotti, Milagros Gorgas y Berenice Olmedo, "La regulación provincial del principio de oportunidad. Sistematización comparativa de las legislaciones provinciales que receptan institutos de oportunidad procesal", Academia Nacional de Derecho y Ciencias Sociales de Córdoba, Instituto de Ciencias Penales, 2011, pp. 1-57, en http://www.acaderc.org.ar/doctrina/articulos/la-regulacion-provincial-de-principio-de/ at_download/file fecha de consulta: 4 de julio de 2021.

Alcácer Guirao, Rafael, "Diversidad cultural, intolerancia y derecho penal", Revista Electrónica de Ciencia Penal y Criminología 18-11 (2016), pp. 1-55.

Asamblea General de las Naciones Unidas, Pacto Internacional de Derechos Civiles y Políticos, Resolución 2200 A (XXI), de 16 de diciembre de 1966.

Asúa Batarrita, Adela, “Criminología y multiculturalismo. Medidas internacionales y propuestas de tratamiento jurídico para la erradicación de la mutilación genital femenina", Cuaderno del Instituto Vasco de Criminología 18 (2004), pp. 83-102.

Bernardi, Alessandro, "El derecho penal entre la globalización y el multiculturalismo", en Revista de Derecho Penal contemporáneo 4 (2003), pp. 13-38.

103 Carnevali, “El multiculturalismo", op. cit., p. 23. 
Bonilla Maldonado, Daniel, "Indígenas urbanos y derechos culturales: los límites del multiculturalismo liberal", Revista Direito GV 7-2 (2011), pp. 569604. https://doi.org/10.1590/S1808-24322011000200009

Borja Jiménez, Emiliano, "Globalización y concepciones del derecho penal", en Revista Estudios Penales y Criminológicos 29 (2009), pp. 141-206.

Borja Jiménez, Emiliano, “Justicia penal preventiva y Derecho penal de la globalización: proyecciones en el ámbito del terrorismo", en ADPCP LXX (2017), pp. 27-71.

Carducci, Michele, "El multiculturalismo. Entre círculo hegeliano y constitucionalismo de la alteridad", en Multiculturalismo y derecho penal, Cizur Menor, Thomson Reuters, 2012, pp. 83-93.

Carnevali, Raúl, "El multiculturalismo: un desafío para el Derecho penal moderno", en Revista Política Criminal 2 (3) (2007), pp. 1-28.

Cerezo Mir, José, "La regulación del error de prohibición culturalmente condicionado en el Código Penal peruano", en Universitas Vitae: homenaje a Ruperto Núñez Barbero, Salamanca, Universidad de Salamanca, 2008, pp. 101-108.

Chiu, Daiana, "The cultural defense: Beyond exclusion, assimilation and guilty liberalism", California Law Review 82 (4), (1994), pp. 1053- 1126. https:// doi.org/10.2307/3480939

Cisneros Ávila, Fátima, Derecho penal y diversidad cultural: los comportamientos culturalmente motivados, Málaga, Universidad de Málaga, 2017, en https:// riuma.uma.es/xmlui/handle/10630/14991, fecha de consulta: 05 de junio de 2021.

Consejo de Derechos Humanos de las Naciones Unidas, Declaración de las Naciones Unidas sobre los derechos de los campesinos y de otras personas que trabajan en las zonas rurales, Resolución A/HRC/39/L.16 de 26 de septiembre de 2018.

Consejo de Derechos Humanos de las Naciones Unidas, Declaración de las Naciones Unidas sobre los derechos de los campesinos y de otras personas que trabajan en las zonas rurales, Resolución A/HRC/39/L.16 de 26 de septiembre de 2018.

Corral Talciani, Hernán, Cómo hacer una tesis en Derecho. Curso de metodología de la investigación jurídica, Santiago, Editorial Jurídica de Chile, 2008.

Cury, Enrique, Derecho Penal, Parte General, 9 ed., Santiago, Universidad Católica de Chile, 2009.

De Maglie, Cristina, Los delitos culturalmente motivados. Ideologías y modelos penales, Madrid, Marcial Pons, 2012. 
Defensoría Penal Pública de Chile, Aspectos culturales de la defensa de imputados indígenas, Santiago, Defensoría Nacional de Chile, 2016.

Díaz, Juliana, "La aleatoriedad de la condición de víctimas y/o victimarios de la infancia y adolescencia en el conflicto armado colombiano", CES Derecho 10 (2) (2019), pp. 566-590. https://doi.org/10.21615/cesder.10.2.2

Dundes Renteln, Alison, "The use and abuse of the cultural defense", en Multicultural Jurisprudence. Comparative perspective on the cultural defense, Oxford, Hart Publishing, 2010.

Dupré, Catherine, The Age of Dignity, Human Rights and Constitutionalism in Europe, Oxford, Hart, 2015.

Faundes, Juan Jorge, “Derecho fundamental a la identidad cultural de los pueblos indígenas: un nuevo paradigma en la defensa penal indígena en Chile frente al Estado de Derecho hegemónico", Izquierdas 45 (2019), pp. 51-78. https://doi.org/10.4067/S0718-50492019000100051

Ferreira Monte, Mario, “Multiculturalismo y derecho penal en el espacio lusófono. Prueba de una solución de restauración para el problema de los delitos motivados culturales", en Multiculturalismo y derecho penal, Cizur Menor, Thomson Reuters, 2012, pp. 117-132.

Gajardo Falcón, Jaime, “El multiculturalismo, su recepción normativa y perspectivas en Chile y Bolivia, un estudio comparado", Universidad de Chile, 2012, en http://repositorio.uchile.cl/handle/2250/112833, fecha de consulta: 15 de junio de 2021.

Gilson, J., L'etude du droit romain compare aux autres droits de l'antiquite, Paris, De Gruyter, 1899.

Gracia Martín, Luis, “La 'adecuación social' como 'el cierre normativo' de lo injusto en el finalismo y el abismo sistemático que la distancia de los criterios de la doctrina de la imputación objetiva", Revista Derecho penal, Constitución y Derechos (2013), pp. 228-251.

Gracia Martín, Luis, "La estructura dogmática y la función político criminal de la 'adecuación social' como 'cierre normativo' de lo injusto", Revista Argentina de Derecho Penal y Procesal Penal 5 (2012), en https://ar.ijeditores.com/ pop.php?option=articulo\&Hash=aacb36002b99246b6d56067ce2596819, fecha de consulta: 05 de junio de 2021.

Hurtado Pozo, José, “Derecho penal y diferencias culturales: el caso peruano”, Derecho penal y criminología 29-96 (2008), pp. 59-94. 
Hurtado Pozo, José, "Derecho penal, multiculturalismo y pueblos nativos", Université de Fribourg, 2014, en http://perso.unifr.ch/derechopenal/assets/ files/articulos/a_20140608_03.pdf, fecha de consulta: 14 de junio de 2021.

Kalinsky, Beatriz, Justicia, cultura y derecho penal, Buenos Aires, Ad-Hoc, 2000.

Kymlicka, Will, "Federalismo, nacionalismo y multiculturalismo", Revista Internacional de Filosofía Política 7 (1996), pp. 20-54.

Kymlicka, Will, Ciudadanía multicultural, Traducido por Carmen Castell, Barcelona, Paidós, 1996.

Legal Information Institute, Cornell Law School, "Diminished Capacity", en https://www.law.cornell.edu/wex/diminished_capacity, fecha de consulta: 15 de junio de 2021.

Lucero Pantoja, Jairo Enrique, "Desobediencia civil cuestión de tradiciones jurídicas o de composiciones y desestructuraciones sociales", CODEX 1 (1), 2015, pp. 107-131.

Lucero Pantoja, Jairo Enrique, "El juez multinivel y la transversalidad de garantías. Un acercamiento a los escenarios fácticos en América y Europa", Opinión Jurídica 20 (41) (2021), pp. 71-99. https://doi.org/10.22395/ojum. v20n41a2

Lucero Pantoja, Jairo Enrique, "La exculpación como criterio punitivo frente a delitos conexos a la rebelión en contextos de conflicto armado interno: una relectura del quehacer del derecho penal en procesos de pacificación", Revista Derecho PUCP 85 (2020), pp. 321-371. https://doi.org/10.18800/derechopucp.202002.010

Luzón Peña, Diego Manuel, "Actuación en conciencia y objeción de conciencia como causa de justificación y como causa de exculpación frente a la punición del delincuente por convicción", Indret 1 (2013), pp. 1-22. https://doi. org/10.5377/derecho.v0i17.1580

Luzón Peña, Diego-Manuel, "Alcance y función del Derecho penal", Anuario de Derecho Penal y Ciencias Penales 42 (1) (1989), pp. 5-54.

Maqueda Abreu, María Luisa y Patricia Laurenzo Copello, El Derecho penal en casos. Parte general. Teoría y Práctica, Valencia, Tirant lo Blanca, 2017.

Martínez, María Josefina, “Recensión García Vitor, Enrique: Diversidad cultural y Derecho Penal", Revista Nueva Doctrina Penal de la Universidad Nacional del Litoral, (1996).

Meini, Iván Imputación y responsabilidad penal. Ensayos de Derecho penal, Lima, Ara Editores, 2012. 
Monateri, Pier Giuseppe, "A quest for the multicultural origins of the "Western Legal Tradition", Hastings Law Journal 50 (2003), pp. 1-72.

Monge Fernández, Antonia, El extranjero frente al Derecho Penal: el error cultural y su incidencia en la culpabilidad, Barcelona, Bosch Editor, 2008.

Moreira, Manuel Alberto, "El concepto de cultura en el derecho", Revista Civitas 8 (3) (2008), pp. 466-481. https://doi.org/10.15448/1984-7289.2008.3.4870

Moreno, Isidoro, "Mundialización, globalización y nacionalismos: la quiebra del modelo de Estado-nación", Cuadernos de Derecho judicial 6 (1998), pp. 11-80.

Nacarino Lorente, José María, “Obrar en el cumplimiento de un deber por las fuerzas y cuerpos de seguridad (Correcta utilización de la fuerza policial)", Universidad de Valencia, 2015, en https://core.ac.uk/download/ pdf/71052381.pdf, fecha de consulta: 05 de mayo de 2021.

Ordeig, Gimbernat, ¿Qué es la imputación objetiva?, Estudios de Derecho penal, 3ra. edición, España, Tecnos, 1990.

Organización Internacional del Trabajo (OIT), Convenio 169, Declaración de las Naciones Unidas sobre los Derechos de los Pueblos Indígenas, 1989.

Pasillas, Enrique, "Multiculturalismo y derechos fundamentales en el noroeste de México: el caso de la tribu yaqui", Revista Estudios Fronterizos 19 (2018), pp. 1-26. https://doi.org/10.21670/ref.1808008

Pérez de la Fuente, Óscar, "Delitos culturalmente motivados. Diversidad cultural, derecho e inmigración", European Journal of Legal Studies 5 (1) (2012), pp. 65-95.

Prittwitz, Cornelius, "Skizzen zu Strafrecht und Kriminalpolitik in Zeiten der Globalisierung", en Strafrechtsprobleme an der Jahrtausendwende, Alemania, Deutsch-Griechisches - Symposium Rostock, 2000, pp. 163-175.

Prittwitz, Cornelius, "Sociedad del riesgo y derecho penal", en Crítica y justificación del Derecho penal en el cambio de siglo, La Mancha, Universidad de Castilla, 2003, pp. 259-287.

Rettig Espinoza, Mauricio Alfredo, "Desarrollo previsible de la relación entre la antijuridicidad y la culpabilidad", Revista de Derecho 22 (2) (2009), pp. 185-203. https://doi.org/10.4067/S0718-09502009000200010

Roxin, Claus, "El concepto de bien jurídico como instrumento de crítica legislativa sometido a examen", Revista Electrónica de Ciencia Penal y Criminología 15 (2013), pp. 1-27.

Roxin, Claus, Derecho penal parte general, t I, Fundamentos de la estructura de la teoría del delito, Madrid, Civitas, 1997. 
Roxin, Claus, Strafrecht. Allgemeiner Teil. Band I. Grundlagen. Der Aufbau der Veerbrechenslehre, 4 ed., Berlín, Verlag C. H. Beck, 2006.

Royo, Manuela, "Derecho Penal e interculturalidad como manifestación del principio de igualdad", Política criminal 10-19 (2015), pp. 362-389. https:// doi.org/10.4067/S0718-33992015000100012

Rusconi, Maximiliano, "Política criminal y error de prohibición", Revista Guatemalteca de Ciencias Penales 'Justicia Penal y Sociedad' 4 (6) (1997), pp. 71-88.

Sánchez-Ostiz, Pablo, "Principios y reglas como base para un modelo argumentativo intercultural de derecho penal", en Multiculturalismo y derecho penal, Cizur Menor, Thomson Reuters, 2012, pp. 41-68.

Schneider Sergio y Fabio Escher, La construcción del concepto de agricultura familiar en América Latina, Chile, FAO, 2012.

Silva Sánchez, Jesús María, "Reflexiones sobre las bases de la política criminal”, Revista de Derecho de la Universidad Católica del Norte, 8 (2001), pp. 189-197. https://doi.org/10.22199/S07189753.2001.0001.00010

Silva Sánchez, Jesús María, La expansión del Derecho Penal. Aspectos de la política criminal en las sociedades occidentales, 2 ed., Madrid, Civitas, 2001.

Spósito, Carolina, “Error de prohibición”, Universidad de Belgrano, 2003, en http://repositorio.ub.edu.ar/bitstream/handle/123456789/173/95_sposito. pdf? sequence=2\&isAllowed=y, fecha de consulta: 27 de junio de 2021 .

Taylor, Charles, El multiculturalismo y la "política del reconocimiento", México D.F., Fondo de Cultura Económica, 1993.

van Broeck, Jeroen, "Cultural defence and culturally motivated crimes (cultural offences)", European Journal of Crime 9 (1) (2001), pp. 1-52. https://doi. org/10.1163/15718170120519282

Vásquez Vásquez, Francisco Javier, “Impacto de la globalización en el mundo jurídico", Revista Opinión Jurídica, 8 (15) (2009), pp. 17-28.

Verón Bustillo, Emilio Javier, La protección del patrimonio cultural contra el tráfico ilícito de bienes culturales, Bogotá, Dykinson, 2017. https://doi.org/10.2307/j. $\mathrm{ctt} 22 \mathrm{p} 7 \mathrm{~h} 01$

Vogel, Joachim, "Derecho penal y globalización", Anuario de la Facultad de Derecho de la Universidad Autónoma de Madrid 9 (2005), pp. 113-126.

Weiber, Bettina, “Prevención mediante el derecho penal: ¿es el derecho penal un medio adecuado contra el omnipresente miedo de atentados terroristas?", en Multiculturalismo y derecho penal, Cizur Menor, Aranzadi-Thomson Reuters, 2012, pp. 171-188. 
Yringoren Fajardo, Raquel, "Pluralismo jurídico, derecho indígena y jurisdicción especial en los países andinos", El otro Derecho 30 (2004), pp. 171-195.

Zaffaroni, Eugenio Raúl, Derecho Penal, Buenos Aires, Ediar, 2000.

Zaffaroni, Eugenio, Derecho Penal. Parte General, Buenos Aires, Ediar, 2002.

\section{Jurisprudencia}

Cámara Nacional en lo Criminal y Correccional de Argentina, Causa "A.L.L" de 21 de febrero de 2013, Sala I- 81-13, Juzgado de Instrucción 4/113. Magistrados Alfredo Barbarosch, Jorge Luis Rimondi y Luis María Bunge Campos.

Corte Constitucional de Colombia, Sentencia SU-510 de 18 de septiembre de 1998, M. P. Eduardo Cifuentes Muñoz.

Corte Constitucional de Colombia, Sentencia T-002 de 11 de enero de 2012, M. P. Juan Carlos Henao.

Corte Constitucional de Colombia, Sentencia T-397 de 29 de julio de 2016, M. P. Gabriel Eduardo Mendoza Martelo.

Corte Constitucional de Colombia, Sentencia T-617 de 5 de agosto de 2010, M. P. Luis Ernesto Vargas Silva.

Corte Constitucional de Colombia, Sentencia T-975 de 18 de diciembre de 2014, M. P. Jorge Ignacio Pretelt.

Tribunal Constitucional de España, Sentencia 154/2002 de 18 de julio de 2002.

Tribunal de Juicio Oral de Calama (Chile), Caso Andrés Arsenio Plaza RITA, RIT: 138-2015, RUC: 1401069965-8, 12 de agosto de 2015.

Tribunal de Juicio Oral en lo penal de Arica (Chile), Caso Ángel Hugo Velázquez Zambrana, RIT: 27-2015, RUC: 1410018700-1, 2 de marzo de 2015.

Tribunal Supremo de España, Sentencia 8697/2007. 